\title{
基于给体-受体-给体型稠环模块的小分子光伏材料的研究进展
}

\author{
戴学新*, $a, b$ 成晓东 ${ }^{a}$ 阚志鹏 $b$ 肖泽云 $b$ \\ 段泰男 $b$ 胡 超*, $b$ 陆仕荣*, $b$ \\ ( ${ }^{a}$ 黔南民族师范学院化学化工学院 贵州都匀 558000) \\ ( ${ }^{b}$ 中国科学院重庆绿色智能技术研究院有机半导体研究中心 重庆 400714)
}

\begin{abstract}
摘要＼cjkstart给体-受体-给体(Donor-Acceptor-Donor, D-A-D)型稠环及其衍生物因具有共轭平面结构大、载流子迁移率高、吸 光性能优异和光热稳定性等优点, 被应用于太阳能电池中, 并获得了优异的光伏性能. 概述了基于 D-A-D 型稠环的小 分子光伏材料的最新研究进展, 总结了该类材料分子结构与其光伏性能之间的关系.
\end{abstract}

关键词＼cjkstart稠环; 太阳能电池; 小分子; 有机光伏材料

\section{Research Progress on Small-Molecule Photovoltaic Materials Based on Donor-Acceptor-Donor Type Polycyclic Aromatic Hydrocarbons}

\author{
Dai, Xuexin ${ }^{*, a, b} \quad$ Cheng, Xiaodong ${ }^{a} \quad$ Kan, Zhipeng $^{b} \quad$ Xiao, Zeyun ${ }^{b}$ \\ Duan, Tainan $^{b} \quad \mathrm{Hu}, \mathrm{Chao}^{*, b} \quad \mathrm{Lu}$, Shirong*,b \\ ( ${ }^{a}$ School of Chemistry and Chemical Engineering, Qiannan Normal University for Nationalities, Duyun, Guizhou 558000) \\ ( ${ }^{b}$ Organic Semiconductor Research Center, Chongqing Institute of Green and Intelligent Technology, \\ Chinese Academy of Science, Chongqing 400714)
}

\begin{abstract}
Donor-acceptor-donor (D-A-D) type polycyclic aromatic hydrocarbon and its derivatives have been widely used in the design of photovoltaic materials and have made great breakthrough in recent years, due to their advantages of unique large planar structure, high charge mobility, excellent light absorption performance, thermal and light stability. The latest research progress of small-molecule photovoltaic materials based on D-A-D type polycyclic aromatic hydrocarbons is reviewed. The relationships between photovoltaic properties and the molecular structures are analyzed systematically.

Keywords polycyclic aromatic hydrocarbon; solar cell; small-molecule; organic photovoltaic material
\end{abstract}

太阳能是一种安全、洁净、可再生能源, 它的开发 及其应用被认为是解决当前人类面临的能源危机和环 境污染两大严峻问题的重要手段. 太阳能电池可以将太 阳能直接转换为电能, 是太阳能利用的最有效途径. 近 年来, 染料敏化太阳能电池(Dye-sensitized solar cells, DSSCs)、有机太阳能电池(Organic solar cells, OSCs) 和钙 钛矿太阳能电池(Perovskite solar cells, PSCs)等因性能 易于调控、可溶液加工成本低廉、可进行大规模生产等 的优势, 在科学研究和工业发展上具有较大潜力, 引起

\begin{abstract}
了人们的广泛研究.
相对于纯粹由富电子体系构成的大面积共轭稠环, 给体-受体-给体(Donor-Acceptor-Donor，D-A-D)型稠 环模块不仅具有大而刚性的平面共轭结构, 而且模块内 存在的推-拉电子体系, 有利于 $\pi$ 电荷的离域, 提高了载 流子传输速率, 有利于摩尔消光系数的提升和吸光范围 的拓宽, 是近年来发展起来的一类光伏材料构建单元. 根据给体-受体-给体(Donor-Acceptor-Donor, D-A-D) 型稠环结构的特点, 可以通过改变中间吸电子单元和两
\end{abstract}

\footnotetext{
* Corresponding authors. E-mail: daixuexin@sgmtu.edu.cn; huchao@cigit.ac.cn; lushirong@cigit.ac.cn Received May 10, 2020; revised July 28, 2020; published online September 15, 2020.

Project supported by the National Natural Science Foundation of China (No. 21762036), the Science and Technology Foundation of Guizhou Province (No. LH[2015]7706) and the Education Department of Guizhou Province (No. KY[2018]422).

国家自然科学基金(No. 21762036)、贵州省科技厅(No. LH[2015]7706)和贵州省教育厅(No. KY[2018]422)资助项目。
} 
侧给电子杂环等方式进行修饰和衍生, 从而对相应材料 的光物理、电化学和堆积方式等方面的性能进行调节, 最终实现光伏性能的调整和提高. D-A-D 型稠环自诞生 以来就受到了光伏材料研究者的关注, Michinobu 等 ${ }^{[1]}$ 和 周二军等 ${ }^{[2]}$ 分别总结了若干 D-A-D 型稠环模块在聚合 物太阳能电池中的应用. 近年来, 基于二噻吩并喹喔啉 (DTQ)和二(噻吩并吡咯)并苯并噻二唑(DTPBT)等多种 D-A-D 型稠环模块的小分子光伏材料已经被报道(图 1), 基于它们的器件也取得了显著的进展. 其中, 含 DTQ 单 元的有机 DSSCs 的光电转换效率 (PCE) 也达到了 $8.65 \%{ }^{[3]}$; 以 DTTPFT 为核心的小分子受体材料的 OSCs 的 PCE 已经接近 $18 \%{ }^{[4]}$; 基于 BTTI 的空穴传输材料的 钙铁矿太阳能电池的 PCE 已高于 $21 \%{ }^{[5]}$. D-A-D 型稠环 及其衍生结构已经成为了一类极为重要的有机小分子 光伏材料构建单元. 本文将介绍基于 D-A-D 型稠环的 小分子在 DSSCs、OSCs 等方面等领域中的应用, 并讨 论该类材料分子结构与其光伏性能之间的联系.

\section{1 常见 D-A-D 型稠环的合成策略}

目前常见的 D-A-D 型稠环的合成策略可以归纳成<smiles>c1cc2c3nonc3c3nonc3c2s1</smiles>

DTBF<smiles>C1=Cc2c3c(c4sccc4c2=N1)=CC=N3</smiles><smiles></smiles>

BTI
以下两类：(1)以缺电子中心向外扩大共轭平面形成 D-A-D 型稠环 ${ }^{[6]}$ ，如 DTPBT、 DTBT 和 DTTPBT 等都是 通过这一方式得到; (2)向富电子的原料引入吸电子基团 并通过适当的反应形成多种稠环 ${ }^{[7]}$, 如 DTBF、DTQ 和 BTTI 等都可用这一策略获得(Scheme 1).

\section{2 基于 D-A-D 型稠环的有机敏化染料}

DSSCs 因廉价高效、光电转化率可观、制备工艺简 单和材料来源丰富等优点自诞生以来就吸引了大量学 术机构和商业公司的关注和研究 ${ }^{[8-15]}$. 通常情况下, DSSCs 由透明的导电玻璃基片、多孔纳米晶二氧化钛薄 膜光阳极、染料敏化剂、电解质溶液和对电极 5 个部分 组成 ${ }^{[7]}$. 其中, 染料敏化剂是整个 DSSCs 系统的核心部 分, 负责吸收太阳光子生成电子并将电子传输至光阳 极, 对 DSSCs 的光电转换效率(PCE)有着直接影响.

有机光敏染料材料来源丰富, 结构多种多样, 易于 设计合成和调节. 同时可以设计成不同颜色和透明度的 电池, 增加产品的美观度和趣味性 ${ }^{[10-14]}$. 给体 $-\pi$ 桥一受 体(D- $\pi-A)$ 结构是当前有机敏化染料的主要形式, $\pi$ 桥可 以有效拓宽染料光响应范围并提高摩尔消光系数, 有利<smiles>O=c1[nH]c(=O)c2c3sccc3sc2c2sc3ccsc3c12</smiles>

BTTI<smiles></smiles>

DTTPBT<smiles>c1cc2[nH]c3c(c2s1)=c1c=3c2nsnc2c2c1[nH]c1ccsc12</smiles>
DTPBT<smiles></smiles>

DTTBT<smiles>C1=Cc2[nH]c3c(c2Nc2ccsc2-3)-c2n[nH]nc21</smiles>

DTBT

图 1 小分子光伏材料中常见的 D-A-D 稠环核心结构式及其缩写

Figure 1 Common D-A-D fused ring core structure formula and its abbreviation in small molecule photovoltaic materials<smiles>O=[N+]([O-])c1c([N+](=O)[O-])c(Br)c2nsnc2c1Br</smiles><smiles>CCCC[Sb]c1cccs1</smiles>
$\frac{\mathrm{PdCl}_{2}\left(\mathrm{PPh}_{3}\right)_{2}}{\mathrm{THF}, \text { refulx }}$<smiles>O=[N+]([O-])c1c(-c2cccs2)c(-c2ccc(F)s2)c2nsnc2c1[N+](=O)[O-]</smiles>
$\mathrm{P}(\mathrm{OEt})_{3}$ o-DCB, $180^{\circ} \mathrm{C}$<smiles></smiles>

DTPBT

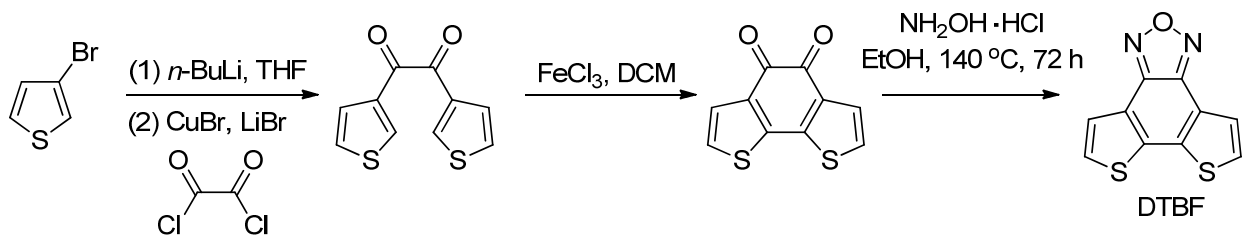

图式 $1 \mathrm{DTPBT}^{[6]}$ 与 $\mathrm{DTBF}^{[7]}$ 的制备路线

Scheme 1 Synthetic routes of DTPBT ${ }^{[6]}$ and $\mathrm{DTBF}^{[7]}$ 
于 PCE 的提高. D-A-D 型稠环具有大平面共轭结构及合 适的前线轨道能级，是一类非常优异的 $\pi$ 桥.

2014 年, 曹德榕课题组 ${ }^{[16]}$ 报道了以 DTPBT 为 $\pi$ 桥 的四个 D- $\pi-A$ 染料分子 $1 \sim 4$, 其中化合物 $1 \sim 3$ 以吩噻 嗪为电子给体, 而 4 以三苯胺为电子给体. 从紫外-可见 吸收光谱可知吩噻嗪的给电子能力较三苯胺强, 故相对 于染料 4 , 化合物 $1 \sim 3$ 的光响应范围更广, 最大系数波 长红移且摩尔消光系数较高. 电化学测试也印证了上述 观点, 化合物 1 3 的前线轨道能级基本相同, 它们的最 高占有轨道 $(\mathrm{HOMO})$ 能级在 $-5.05 \mathrm{eV}$ 左右而最低空有 轨道(LUMO)能级在 $-2.85 \mathrm{eV}$ 左右; 而化合物 4 的 HOMO 能级和 LUMO 能级分别为 -5.19 和 $-2.96 \mathrm{eV}$. 但是, 螺旋桨形的三苯胺较吩噻嗪有更强的抑制聚集能 力, 有利于开路电压 $\left(V_{\mathrm{oc}}\right)$ 的提高. 加入 $1 \mathrm{mmol} \cdot \mathrm{L}^{-1}$ 的我鸟 去氧胆酸 $(\mathrm{CDCA})$ 为共吸附剂后, 上述染料敏化的太阳 能电池的短路电流 $\left(J_{\mathrm{sc}}\right)$ 均有较大的提升, 其中 4 敏化的 太阳能电池获得了 $16.95 \mathrm{~mA} / \mathrm{cm}^{2}$ 的 $J_{\mathrm{sc}}$, PCE 可达 $7.55 \%$.
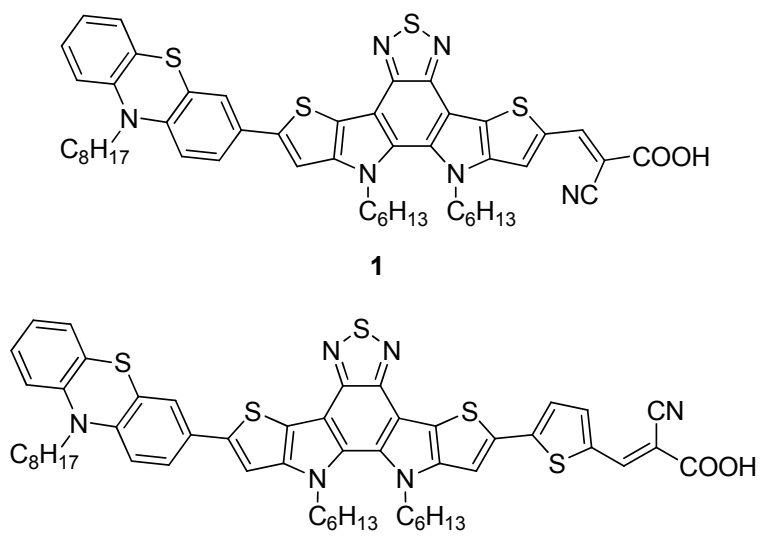

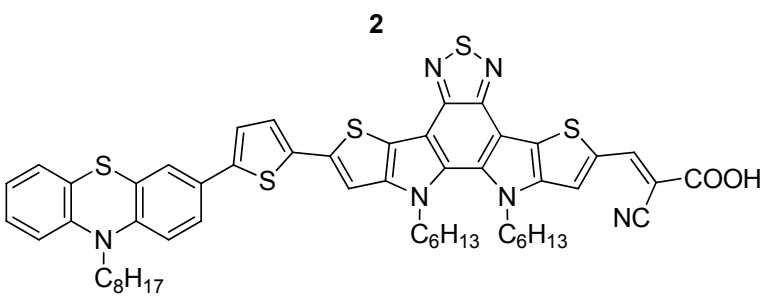

3

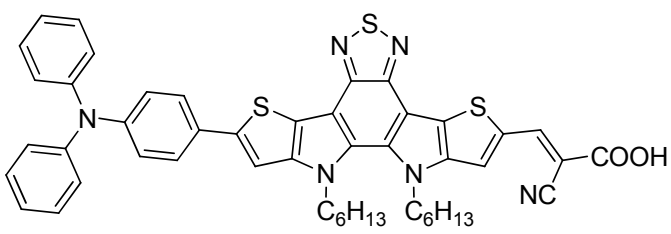

4

相对于苯并噻二唑, 苯并三氮唑可引入烷基链以提 高抗聚集能力. 进一步地, 曹德榕课题[17]组将 DTBT 引 入有机染料中. 得益于 DTBT 的大共轭结构, 化合物
5 $~ 8$ 均拥有较高的摩尔消光系数及较宽的可见光与近 红外光响应范围. 由于结构比较类似, 这些化合物的带 隙基本一致. 化合物 8 敏化的太阳能电池的 $V_{\mathrm{oc}}$ 达 0.723 $\mathrm{V}, \mathrm{PCE}$ 可达 $8.05 \%$. 当使用 $\mathrm{CDCA}$ 作为共吸附剂时, 该 物质敏化的电池 PCE 反而下降, 这说明在 DTBT 环上引 入异辛基，能够较好地抑制 $\mathrm{H}$-聚集.
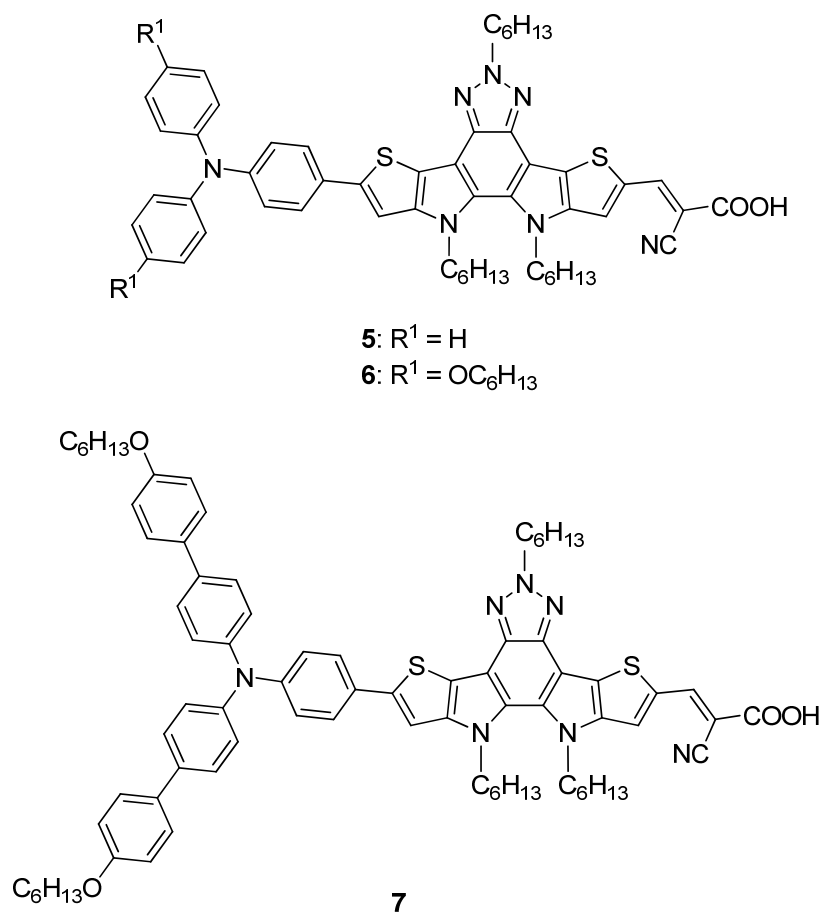

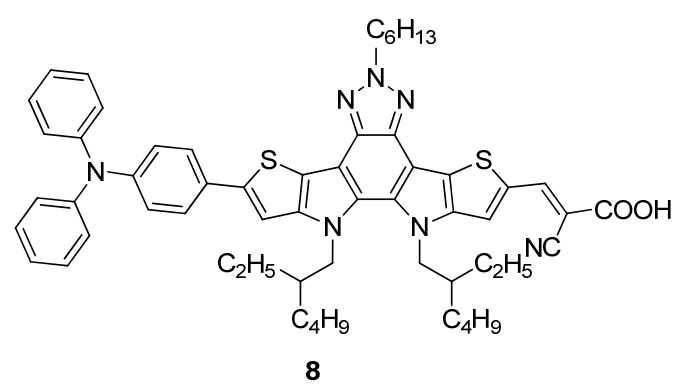

2014 年, 林建村课题组 ${ }^{[18]}$ 报道了以 DTBF 为辅助受 体的 D- $\pi-\mathrm{A}^{\prime}-\pi-\mathrm{A}$ 型有机染料 $9 \sim \mathbf{1 2}$, 并讨论了不同给体 对染料的光物理、电化学及光伏性能的影响. 这些染料 在可见光的最大吸收峰在 462 到 $464 \mathrm{~nm}$ 之间, 但是摩尔 消光系数有明显差异 $\left(\right.$ 最低 $1.70 \times 10^{5} \mathrm{~L} \cdot \mathrm{mol}^{-1} \cdot \mathrm{cm}^{-1}$, 最

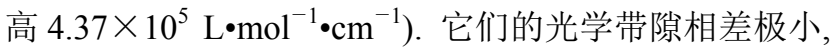
但前线轨道能级差异较大. 因此, 组成敏化太阳电池之 后, PCE 的差异也较大 $(1.42 \% \sim 6.18 \%)$. 值得注意的是, 未加入 $\mathrm{CDCA}$ 作为共吸附剂时，化合物 9 的 PCE 最高; 但是加入 $10 \mathrm{mmol} \cdot \mathrm{L}^{-1}$ 的 $\mathrm{CDCA}$ 作为共吸附剂时, 化合 物 12 的 $V_{\mathrm{oc}} 、 J_{\mathrm{sc}}$ 、填充因子(Fill Factor, $F F$ )均有一定的 提升, PCE 由 $5.98 \%$ 跃升至 $7.33 \%$. 


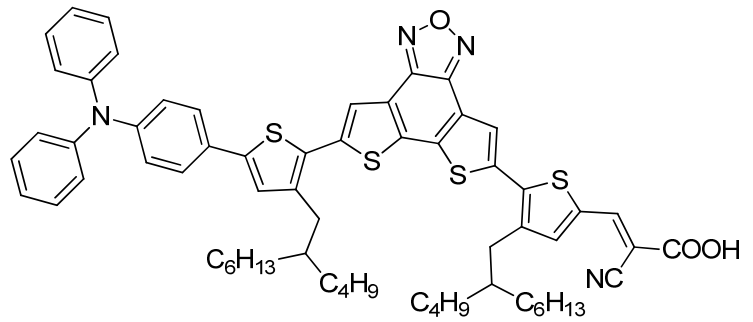

9

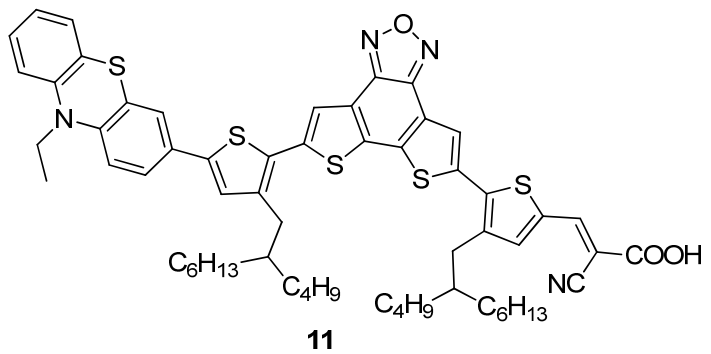

DTQ 具有喹喔啉核心, 可以较为方便地引入烷基 链或烷基苯等基团以达到抑制聚集和提高溶解度的目

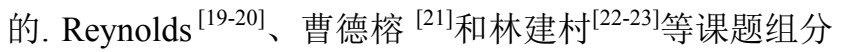
别对这一类物质应用于 DSSCs 做了详细的研究.

2014 年, Reynolds 课题组 ${ }^{[19-20]}$ 设计了一些含 DTQ 结 构的 $\mathrm{D}_{2} \mathrm{~A}$ 染料 $13 \sim 22$, 但是这些染料敏化的器件效率 都不超过 $2 \%$.

2015 年, 曹德榕课题组 ${ }^{[21]}$ 报道了了 5 个基于 DTQ 的有机染料 $23 \sim 27$, 并对电子给体和共轭结构对最终 的光伏表现的影响做了探讨. 化合物 25 中引入了富电 子的 3,4-二氧乙烯基噻吩, 吸光范围最广, 但过高的

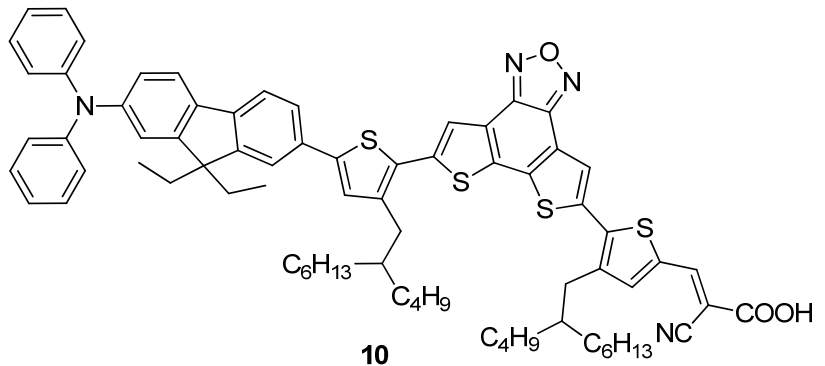

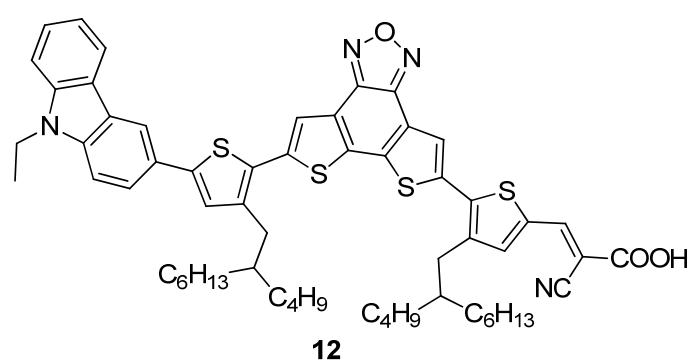

HOMO 能级和较低的电子寿命使得器件的 $V_{\mathrm{oc}}$ 较低, 最 终敏化的电池 PCE 不理想. 化合物 $\mathbf{2 6}$ 和 27 属于典型的 $D-A^{\prime}-\pi-A$ 型有机染料, 苯并噻二唑作为辅助电子受体起 到了延长共轭并控制 HOMO 能级的作用，因此化合物 26 和 27 敏化的器件仍然能够较好地工作; 吲哚啉给电 子能力较三苯胺更强, 故化合物 27 吸光范围较 26 更广, 从而获得了更高的 $J_{\mathrm{sc}}$.

林建村题组 $^{[22-23]}$ 重点考察了 DTQ 核上芳基侧链结 构对染料性能的影响. 他们认为在 DTQ 核上侧链引入 苯基侧链可以抑制 $\mathrm{H}$ 聚集，然而固体紫外和光伏测试均 表明染料 $28 \sim 32$ 在 $\mathrm{TiO}_{2}$ 膜上均有一定程度的聚集 ${ }^{[22]}$.

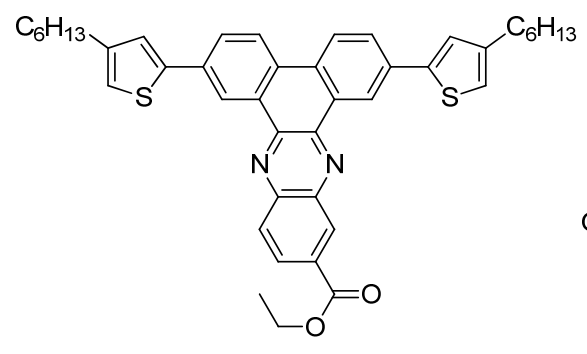

13

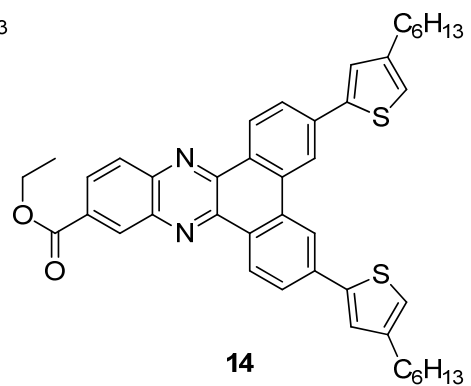<smiles>[R6]C(=O)c1ccc2nc3c4cc(-c5cc(CCCCC)cs5)sc4c4sc(-c5cc(C(C)C)cs5)cc4c3nc2c1</smiles>
17: $\mathrm{R}=\mathrm{H}$

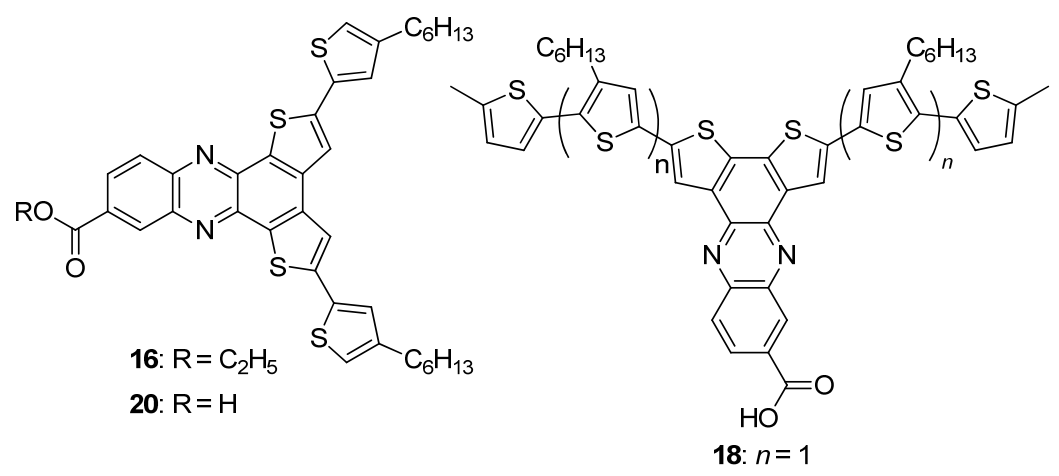

19: $n=2$

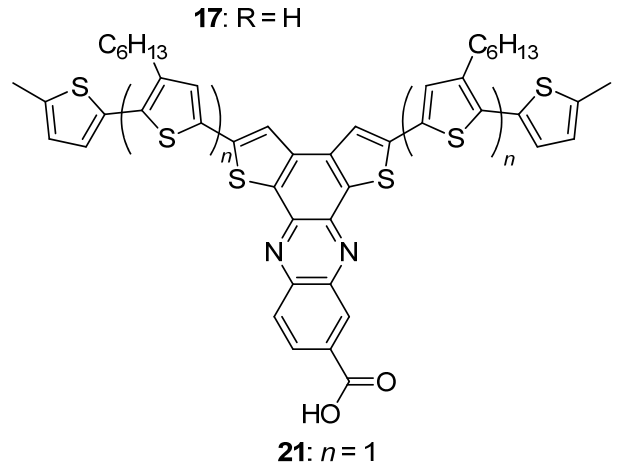

22: $n=2$ 

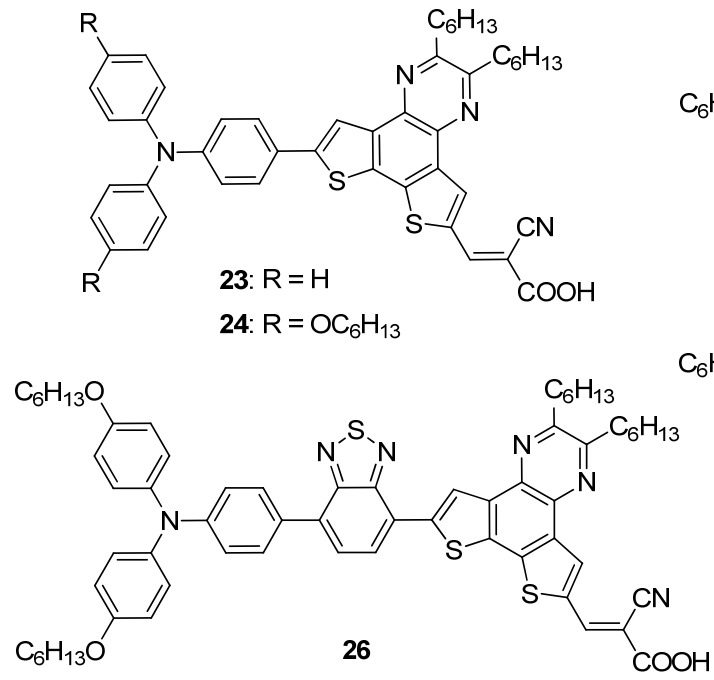

将苯基侧链换成对已氧基苯之后，染料的吸收蓝移了 $12 \mathrm{~nm}$, 这是由于给电子的已氧基苯侧链降低了 DTQ 核 的吸电子能力, 分子内电荷转移强度降低. 在对电子给 体和共轭结构进行优化并添加共吸附剂之后, 最终染料

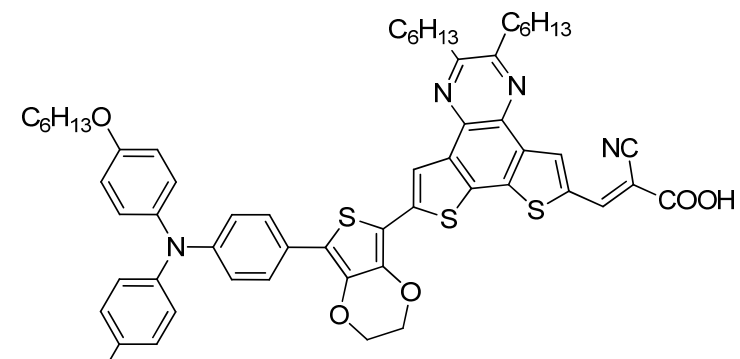

25

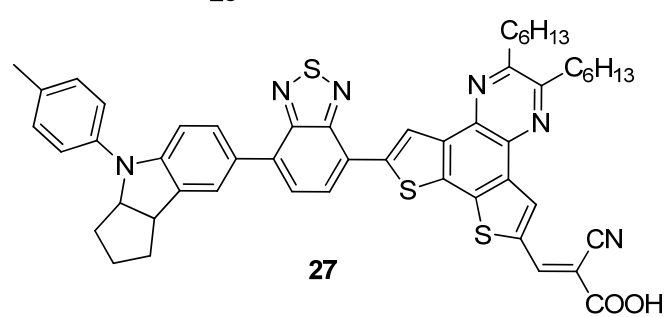

31 敏化的电池 $V_{\mathrm{oc}}$ 为 $0.754 \mathrm{~V}, J_{\mathrm{sc}}$ 为 $15.48 \mathrm{~mA} / \mathrm{cm}^{2}, F F$ 为 $72 \%, \mathrm{PCE}$ 为 $8.41 \%$, 超过了经典染料 N719. 为获得抑 制 $\mathrm{H}$ 聚集能力更优秀的染料，他们 ${ }^{[23]}$ 基于模拟计算的结 果将侧链换成了噻吩衍生物, 设计合成了 4 种新的染料

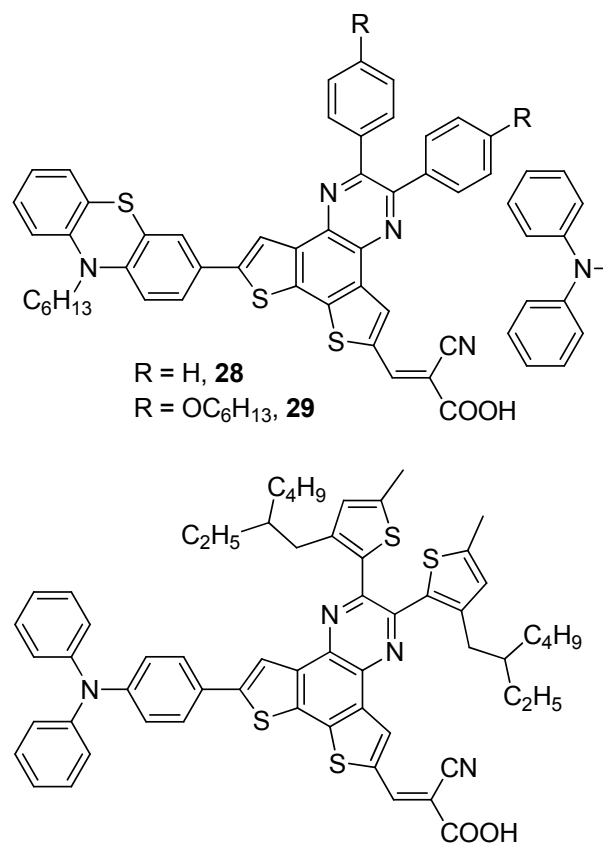

33

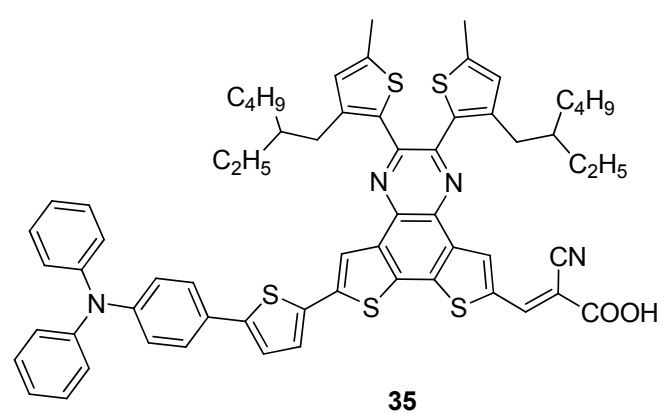<smiles></smiles>

30<smiles>[AlH2]</smiles>

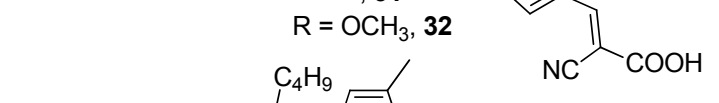<smiles>CCC(C)Cc1cc(C)sc1C(=N)C(=N)c1cc(C)sc1CC(CC)CC</smiles><smiles>Cc1c(N)c2cc(-c3ccc(/C=C(\C#N)C(=O)O)s3)sc2c2sc(-c3ccc(-c4ccc(N(c5ccccc5)c5ccccc5)cc4)s3)cc12</smiles>

36 
33 36. 密度泛函理论(DFT)计算显示, 较之于对己氧 基苯侧链, 噻吩衍生物侧链与 DTQ 核的二面角明显增 大; 紫外一可见光吸收光谱测试也表明这些染料产生聚 集的浓度普遍较化合物 30 高. 这些都预示着化合物 33 36 有着不错的抑制聚集能力. 在未使用 CDCA 的 情况下, 组装成 DSSCs 器件后, 它们的 $V_{\mathrm{oc}}$ 都比化合物 30 敏化的电池高; 其中化合物 34 获得了 $0.788 \mathrm{~V}$ 的 $V_{\mathrm{oc}}$, PCE 为 $8.27 \%$, 优化电解液组成之后, PCE 升至 $8.57 \%$.

Demadrille 等 ${ }^{[3]}$ 合成了系列含有喹喔啉结构的 $D-\pi-A^{\prime}-\pi-A$ 型有机染料, 虽然化合物 37 的光响应范围 不是最宽的, 但得益于 D-A-D 型稠环共轭体系, 材料摩 尔消光系数高, 器件的光生电子寿命较长, 所敏化的器
件获得了 $8.65 \%$ 的 PCE.

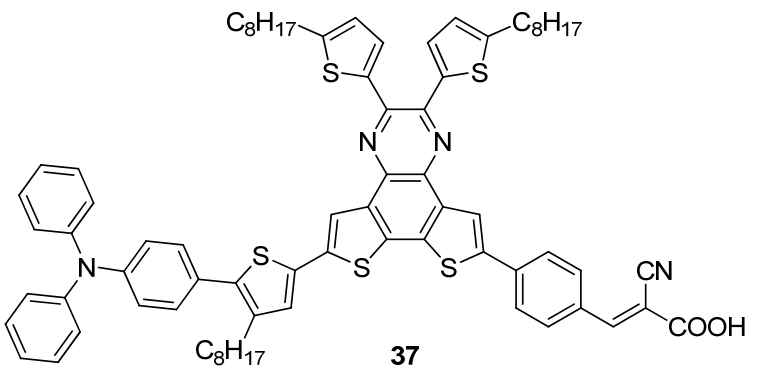

含 D-A-D 型稠环单元的有机染料一般摩尔消光系 数都比较高, 它们组成的光太阳能电池大多获得了较好 的光电转换效率，表 1 总结了本文涉及的染料敏化的太

表 1 染料 $1 \sim 37$ 电池器件的性能

Table 1 Performance of dyes $\mathbf{1} \sim \mathbf{3 7}$ sensitized solar cells

\begin{tabular}{|c|c|c|c|c|c|}
\hline Compd. & $V_{\mathrm{oc}} / \mathrm{V}$ & $J_{\mathrm{sc}} /\left(\mathrm{mA} \cdot \mathrm{cm}^{-2}\right)$ & $F F / \%$ & PCE $/ \%$ & Ref. \\
\hline 1 & $0.664(0.642)^{a}$ & $12.54(14.79)^{a}$ & $60(57)^{a}$ & $5.02(5.42)^{a}$ & [16] \\
\hline 2 & $0.599(0.577)^{a}$ & $9.86(11.87)^{a}$ & $60(59)^{a}$ & $3.54(4.07)^{a}$ & [16] \\
\hline 3 & $0.622(0.673)^{a}$ & $11.15(12.76)^{a}$ & $63(62)^{a}$ & $4.39(5.31)^{a}$ & [16] \\
\hline 4 & $0.726(0.694)^{a}$ & $15.30(16.95)^{a}$ & $62(64)^{a}$ & $6.86(7.55)^{a}$ & [16] \\
\hline 5 & $0.696(0.735)^{a}$ & $11.20(15.03)^{a}$ & $64(68)^{a}$ & $5.01(7.50)^{a}$ & [17] \\
\hline 6 & $0.656(0.700)^{a}$ & $12.19(16.06)^{a}$ & $66(65)^{a}$ & $5.27(7.32)^{a}$ & [17] \\
\hline 7 & $0.694(0.689)^{a}$ & $12.81(13.85)^{a}$ & $66(68)^{a}$ & $5.86(6.47)^{a}$ & [17] \\
\hline 8 & $0.723(0.705)^{a}$ & $16.35(15.95)^{a}$ & $68(65)^{a}$ & $8.05(7.34)^{a}$ & [17] \\
\hline 9 & $0.700(0.720)^{a}$ & $12.60(12.86)^{a}$ & $71(72)^{a}$ & $6.18(6.65)^{a}$ & [18] \\
\hline 10 & $0.600(0.630)^{a}$ & $3.23(4.36)^{a}$ & $72(69)^{a}$ & $1.42(1.91)^{a}$ & [18] \\
\hline 11 & $0.690(0.710)^{a}$ & $10.92(11.44)^{a}$ & $70(69)^{a}$ & $5.27(5.60)^{a}$ & [18] \\
\hline 12 & $0.680(0.700)^{a}$ & $12.43(14.29)^{a}$ & $72(73)^{a}$ & $5.98(7.33)^{a}$ & [18] \\
\hline 13 & 0.520 & 2.24 & 62 & 0.73 & [19] \\
\hline 14 & 0.490 & 2.61 & 53 & 0.66 & [19] \\
\hline 15 & 0.430 & 2.23 & 54 & 0.53 & [19] \\
\hline 16 & 0.440 & 2.81 & 53 & 0.66 & [19] \\
\hline 17 & 0.440 & 2.12 & 58 & 0.55 & [20] \\
\hline 18 & 0.470 & 2.78 & 53 & 0.70 & [20] \\
\hline 19 & 0.520 & 4.97 & 62 & 1.60 & [20] \\
\hline 20 & 0.470 & 2.18 & 66 & 0.68 & [20] \\
\hline 21 & 0.500 & 4.05 & 63 & 1.27 & [20] \\
\hline 22 & 0.520 & 6.01 & 57 & 1.78 & [20] \\
\hline 23 & $0.741(0.707)^{a}$ & $13.11(11.71)^{a}$ & $65(69)^{a}$ & $6.37(5.75)^{a}$ & [21] \\
\hline 24 & $0.662(0.619)^{a}$ & $9.31(6.68)^{a}$ & $65(71)^{a}$ & $4.03(2.94)^{a}$ & [21] \\
\hline 25 & $0.655(0.615)^{a}$ & $9.01(6.46)^{a}$ & $68(67)^{a}$ & $4.01(2.66)^{a}$ & [21] \\
\hline 26 & $0.721(0.698)^{a}$ & $14.51(12.63)^{a}$ & $68(66)^{a}$ & $6.78(5.80)^{a}$ & [21] \\
\hline 27 & $0.685(0.648)^{a}$ & $17.61(12.89)^{a}$ & $59(68)^{a}$ & $7.12(5.71)^{a}$ & [21] \\
\hline 28 & $0.734(0.729)^{a}$ & $13.89(13.76)^{a}$ & $69(73)^{a}$ & $7.06(7.36)^{a}$ & [22] \\
\hline 29 & $0.726(0.740)^{a}$ & $11.67(13.29)^{a}$ & $72(71)^{a}$ & $6.11(6.97)^{a}$ & [22] \\
\hline 30 & $0.736(0.746)^{a}$ & $13.36(13.84)^{a}$ & $73(75)^{a}$ & $7.19(7.73)^{a}$ & [22] \\
\hline 31 & $0.732(0.754)^{a}$ & $14.93(15.48)^{a}$ & $69(72)^{a}$ & $7.59(8.41)^{a}$ & [22] \\
\hline 32 & $0.747(0.758)^{a}$ & $13.36(14.93)^{a}$ & $70(71)^{a}$ & $7.03(8.08)^{a}$ & [22] \\
\hline 33 & 0.748 & 12.12 & 75 & 6.78 & [23] \\
\hline 34 & 0.788 & 14.42 & 73 & 8.27 & [23] \\
\hline 35 & 0.773 & 13.32 & 74 & 7.60 & [23] \\
\hline 36 & 0.763 & 15.08 & 70 & 8.10 & [23] \\
\hline 37 & 0.828 & 14.11 & 74 & 8.65 & [3] \\
\hline
\end{tabular}

${ }^{a}$ Co-sensitived with CDCA. 
阳能电池的光伏性能数据. 然而受制于 DSSCs 理论极 限效率偏低, OSCs、PSCs 发展迅猛等因素, 近两年 D-A-D 型稠环在这方面的应用报道较为少见.

\section{3 基于 D-A-D 型稠环的小分子受体材料}

“稠环电子受体(FREAs)” ${ }^{[24-27]}$ 是近年来 OSCs 领域 的新突破, 并已成为了小分子光伏材料领域 ${ }^{[28-29]}$ 的研究 热点, 是当前世界上最高效的非富勒烯受体体系. D-A-D 型稠环中存在的吸电子单元可能有利于降低电 压损失; 较小分子受体材料中常见的引达省并二噻吩 (indacenodithiophene, IDT) ${ }^{[30]}$ 类单元平面性更好, 有利 于形成有序的 $\pi-\pi$ 堆积和载流子的传输, 因此用于 FREAs 时有其独特的优势 [31].

邹应萍课题组与李永舫团队 ${ }^{[32]}$ 合作 2017 年首次将 D-A-D 型稠环引入 FREAs 中, 以 BZTP 为核心，合成了 化合物 38. 这一化合物热稳定性高, 溶解性好, 易溶于 氯仿、二氯甲烷和邻二氯苯等溶剂; 在 550 到 $900 \mathrm{~nm}$ 范 围内均有较强的吸收, 成膜之后起始吸收波长 $\left(\lambda_{\text {onset }}\right)$ 达 $857 \mathrm{~nm}$, 且消光系数高达 $1.57 \times 10^{5} \mathrm{~cm}^{-1}$; 循环伏安法 测得 HOMO 能级和 LUMO 能级分别为: -5.42 和$3.88 \mathrm{eV}$. 研究表明, 加入体积分数为 $0.25 \%$ 的氯芸及 $120{ }^{\circ} \mathrm{C}$ 热退火组装的太阳能电池器件的空穴传输速率 和电子传输速率分别为: $1.15 \times 10^{-4}$ 和 $1.11 \times 10^{-4} \mathrm{~cm}^{2}$. $\mathrm{V}^{-1} \cdot \mathrm{s}^{-1}$, 较未优化的器件提高了一个数量级, 且二者更 加趋于平衡; 原子力显微镜(AFM) 与透射电镜(TEM)的 检测结果都表明, 后处理对给受体的互穿网络结构产生 了较大影响, 导致粗糙度和晶区尺寸发生显著改变. 最 终经过优化的太阳电池 $V_{\mathrm{oc}}$ 为 $0.84 \mathrm{~V}, J_{\mathrm{sc}}$ 为 12.67 $\mathrm{mA} / \mathrm{cm}^{2}, F F$ 为 $59 \%$, PCE 为 $6.3 \%$.

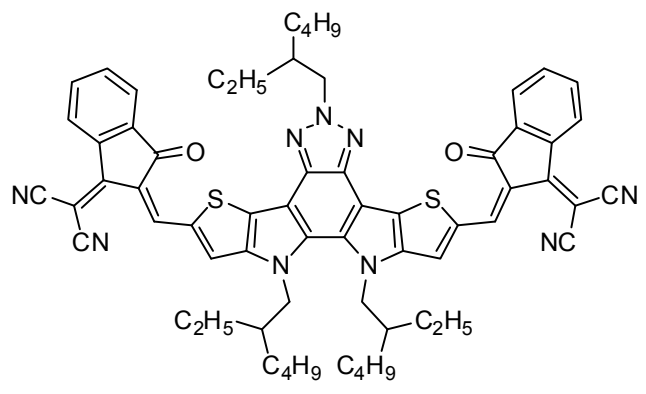

38

上述器件较低的外量子效率值(external quantum efficiency, $\mathrm{EQE}$ )和 $F F$ 限制了光电转换效率的提高. 邹应 萍课题组与李永舫团队 ${ }^{[31]}$ 将 D-A-D 结构中的“D”由噻吩 换成噻吩并 $[3,2-b]$ 噻吩来扩大共轭使得吸收红移, 得到 了化合物 39 和 40. 它们的薄膜的最大吸收峰比溶液中 红移超过了 $60 \mathrm{~nm}$, 说明了这两种化合物在薄膜状态下 存在较强的堆积. 另外, 此分子表现出良好的平面性和
对称性，有利于 $\pi-\pi$ 堆积，从而提高空穴迁移率. 与商 品化的聚合物给体 PBDB-T 组成器件之后, 均可以获得 超过 $22 \mathrm{~mA} / \mathrm{cm}^{2}$ 的短路电流密度，填充因子可达 $70 \%$, PCE 均大于 $13 \%$. 数据表明, 封端基团的不同使得两者 在开路电压上有一定的差异, 并较大地影响了器件的空 穴和电子传输速率. 该课题组对噻吩并 $[3,2-b]$ 噻吩上烷 基链的种类及受体分子的封端基团等做了进一步细致 探讨.

当噻吩并 $[3,2-b]$ 塞吩 3 号位被十一烷基取代时(41), 化合物 41 在溶液中的最大吸收峰为 $720 \mathrm{~nm}$, 较化合物 $\mathbf{2}$ 蓝移 $18 \mathrm{~nm}$, 但成膜之后最大吸收峰反而较 39 红移 ${ }^{[33]}$; 得益于给电子的烷基链, 41 光学带隙变窄为 $1.36 \mathrm{eV}$; 与 PBDB-T 组成器件之后再退火处理能够大幅提升器件的 $J_{\mathrm{sc}}$ 和 $F F$, 加入体积分数为 $0.5 \%$ 的氯荎及 $110{ }^{\circ} \mathrm{C}$ 热退火 优化器件可以获得 $23.28 \mathrm{~mA} / \mathrm{cm}^{2}$ 的 $J_{\mathrm{sc}}, F F$ 为 $63 \%$, PCE 为 $13.26 \%$. 邹应萍课题组与合作者 ${ }^{[34]}$ 将 3 号位的十一烷 基换成正已基以增强结晶性，得到了化合物 42.42 与 PBDB-T 组成的器件 $V_{\mathrm{oc}}$ 为 $0.91 \mathrm{~V}, \mathrm{PCE}$ 为 $13.00 \%$. 当加 入质量分数为 $15 \%$ 的另一小分子受体组成三元器件时, 提高了光电池的短路电流密度, PCE 提升至 $14.11 \%$. 这 预示着了这类分子在多组分有机太阳能电池中也有很 好的应用前景.

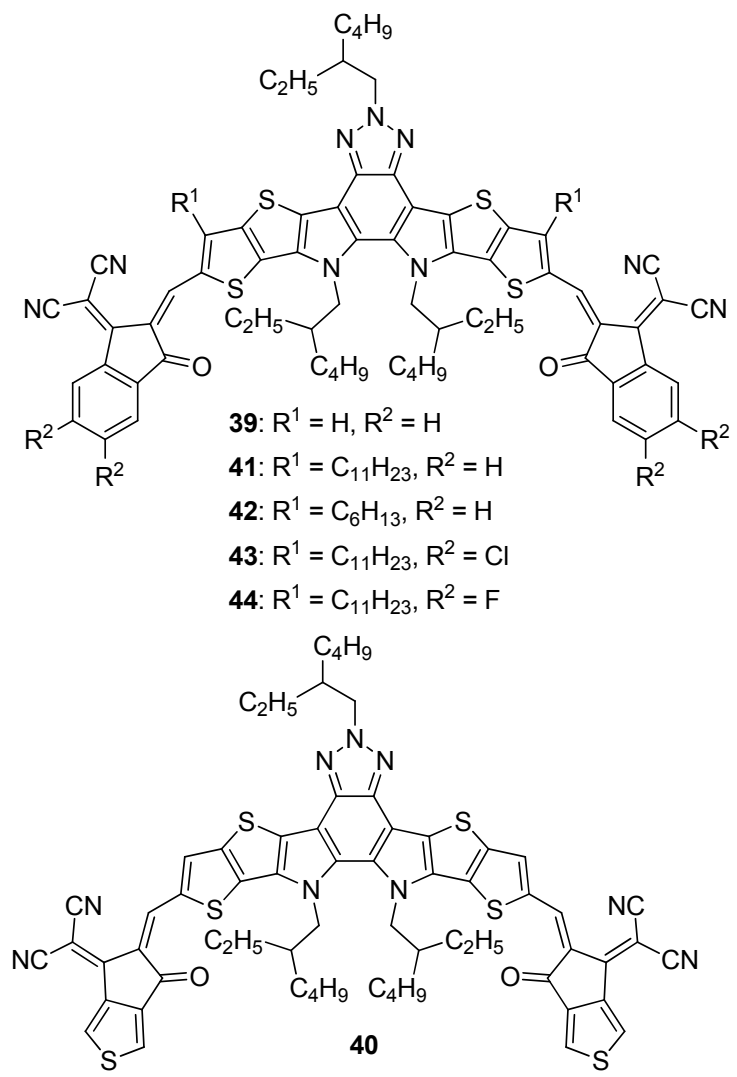

研究表明，采用氟代氰基菛酮封端基团可以有效降 低受体分子的 LUMO 能级, 使得吸收红移并提高电子 
迁移率 ${ }^{[35]}$. 受此研究的启发, 近年来许多研究者在封端 基团上引入卤素以对材料的带隙进行精细调节, 使得吸 收红移, 进一步的研究表明卤素对分子的结晶性亦有较 大影响. 43 是在 41 的基础上将封端基团由氰基狮满二 酮换成二氯代氰基狮满二酮 ${ }^{[36]}$, 其在 600 到 $1000 \mathrm{~nm}$ 范 围内均有较强的吸收, 成膜之后 $\lambda_{\text {onset }}$ 达 $949 \mathrm{~nm}$, 光学带 隙进一步变窄为 $1.36 \mathrm{eV}$; 与 PM- 6 组成的未经优化的器 件的 PCE 达 11.54\%. 加入添加剂 1,8-二碘辛烷(DIO)及 热退火后器件的 $F F$ 从 $59.62 \%$ 提高至 $68.49 \%$, PCE 提升 至 $14.13 \%$. 当封端基团被换成二氟代氰基狮满二酮时, 受体 44 与 PM-6 组成的太阳能电池的非辐射损失仅为 $0.17 \mathrm{eV}$, 获得了 $16.54 \%$ 的 PCE(认证效率为 $15.89 \%)^{[37]}$. 相较于苯并三氮唑, 苯并噻二唑具有更好的结晶性 及吸电子能力, 邹应萍课题组与李永舫团队 ${ }^{[38]}$ 合作将 D-A-D 结构中的“A”换成苯并噻二唑得到了系列化合物 45 和 46. 化合物 45 在氯仿中的最大吸收峰为 $718 \mathrm{~nm}$, 旋涂成膜之后的最大吸收峰比溶液中红移 $65 \mathrm{~nm}$, 在 600 到 $900 \mathrm{~nm}$ 范围内有很强的吸收, 消光系数为 $1.24 \times$ $10^{5} \mathrm{~cm}^{-1}$; 电子传输速率为 $2.11 \times 10^{-4} \mathrm{~cm}^{2} \cdot \mathrm{V}^{-1} \cdot \mathrm{s}^{-1}$, 掠 入射广角 $X$ 射线散射 (GIWAXS)测试显示, 45 纯膜中分 子以垂直于基底的形式排布, 有利于载流子传输. 其 HOMO 能级和 LUMO 能级分别为 -5.5 和 $-3.87 \mathrm{eV}$, 光 学带隙为 $1.38 \mathrm{eV}$, 是一种典型的窄带隙 $\mathrm{n}$ 型受体. 在与 三种中等带隙聚合物给体(J61、TTFQx-T1 和 PBDB-T) 组成电池之后, 优化的器件的 $J_{\mathrm{sc}}$ 均高于 $20 \mathrm{~mA} / \mathrm{cm}^{2}$. 将 45 中噻吩并 $[3,2-b]$ 噻吩单元的 3 号位用十一烷基取代, 他们 ${ }^{[39]}$ 合成了化合物 46 . 化合物 46 在氯仿中的最大吸 收峰为 $731 \mathrm{~nm}$, 成膜之后 $\lambda_{\text {onset }}$ 为 $931 \mathrm{~nm}$, GIWAXS 结果 表明 46 纯膜中分子也以垂直于基底的形式排布; 相较 于 45 , 化合物 46 的 LUMO 能级变为 $-4.10 \mathrm{eV} .46$ 与 PM-6 组成的器件无需优化 PCE 就超过了 $15 \%$. 在加入 体积分数为 $0.5 \%$ 的氯荎及 $110{ }^{\circ} \mathrm{C}$ 热退火后器件的 $F F$ 接近 $75 \%, J_{\mathrm{sc}}$ 超过 $25 \mathrm{~mA} / \mathrm{cm}^{2}$, PCE 提升至 $15.72 \%$ (第三 方认证效率也达到了 $14.90 \%$ 的 $\mathrm{PCE}$ ). 同时, 这一体系 对厚度不敏感, 当活性层厚度达 $300 \mathrm{~nm}$ 时, 仍然能够获 得 $12.63 \%$ 的 PCE，显示了良好的应用前景.

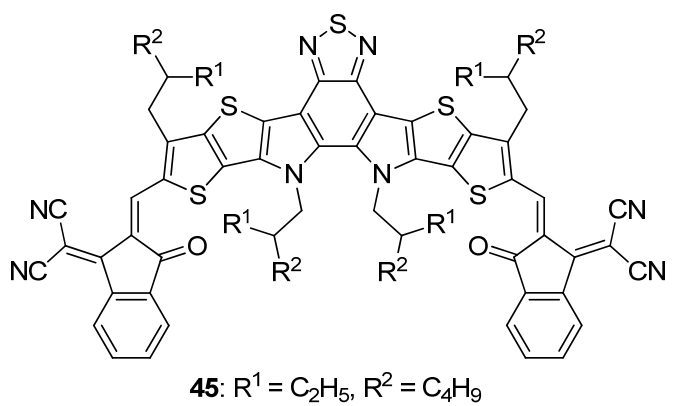

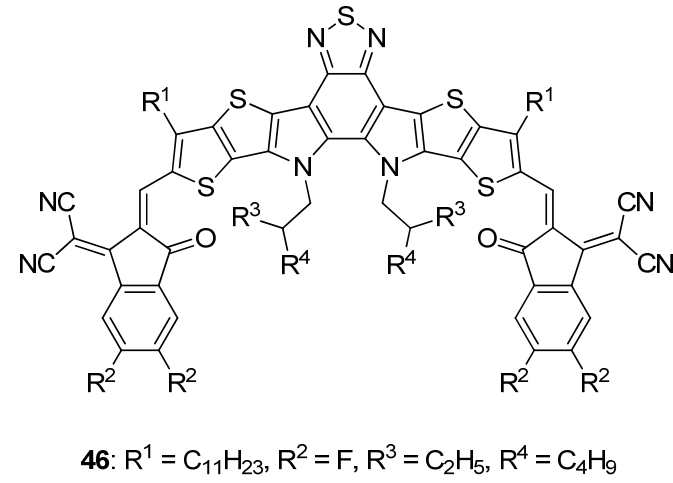

46 优异的光伏表现吸引了许多课题组兴趣. 陆仕 荣课题组 ${ }^{[40]}$ 发现 46 和经典的小分子给体 BTR 搭配能够 获得较高的效率，通过优化给体分子的结构成功提高了 全小分子有机太阳能电池(ASM OSCs)的效率; 朱晓张 课题组 ${ }^{[41]}$ 也报道了类似的研究.

曹锯和黄飞团队 ${ }^{[42]}$ 采用他们课题组开发的聚合物 给体 P2F-EHp 与 46 组成 OSCs, 获得了 $0.81 \mathrm{~V}$ 的 $V_{\mathrm{oc}}$ 和 $26.68 \mathrm{~mA} / \mathrm{cm}^{2}$ 的 $J_{\mathrm{sc}}, F F$ 为 $74.11 \%, \mathrm{PCE}$ 超过了 $16 \%$. 同 时, 他们还比较了 D-A-D 核心单元共轭面积大小对光 伏表现的影响. 将 3-十一烷基噻吩并 [3,2- $b$ 噻吩换成噻 吩时，所得化合物 $\mathbf{4 7}$ 的光吸收范围较 46 蓝移 $100 \mathrm{~nm}$; GIWAXS 结果表明, P2F-EHp 与 46 组成的共混膜以典型 的垂直于基底的形式排布，而 P2F-EHp 与 47 组成的共 混膜更多以平行于基底的形式排布. AFM 测试表明，相 较于化合物 $\mathbf{4 7}, \mathrm{P} 2 \mathrm{~F}-\mathrm{EHp}$ 与 $\mathbf{4 6}$ 组成的共混膜的粗楉度更 小, 聚集不明显; 最终化合物 47 与 $\mathrm{P} 2 \mathrm{~F}-\mathrm{EHp}$ 组成的器件 仅仅获得了 $1.09 \%$ 的 PCE.

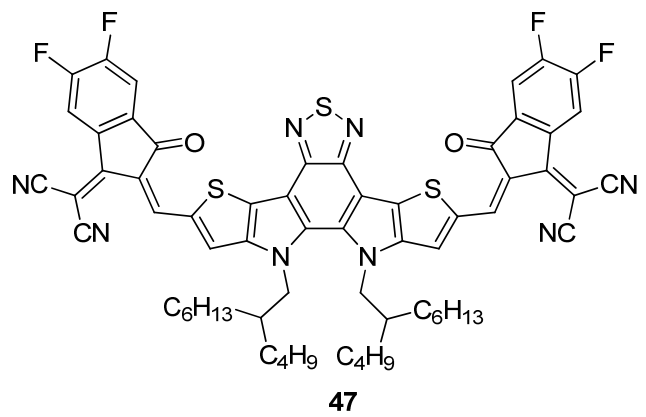

候剑辉课题组 ${ }^{[43]}$ 采用端基工程将 46 的封端基团由 二氟代氰基狮满二酮换成二氯代氰基茚满二酮得到化 合物 48. 相较于 46, 受体 48 的吸收红移了 $20 \mathrm{~nm}$, LUMO 能级降低了 $0.1 \mathrm{eV}$. 一般地, 受体 LUMO 能级降 低将导致器件 $V_{\mathrm{oc}}$ 降低, 但 $\mathbf{4 8}$ 的非辐射损失小于 $\mathbf{4 6}$, 反 而使得基于 48 的器件 $V_{\mathrm{oc}}$ 更高. 采用 PM-6(原文中缩写 为 $\mathrm{PBDB}-\mathrm{TF}$ )与化合物组成的器件的 $V_{\mathrm{oc}}$ 为 $0.867 \mathrm{~V}, J_{\mathrm{sc}}$ 为 $25.4 \mathrm{~mA} / \mathrm{cm}^{2}, \mathrm{PCE}$ 为 $16.5 \%$. 


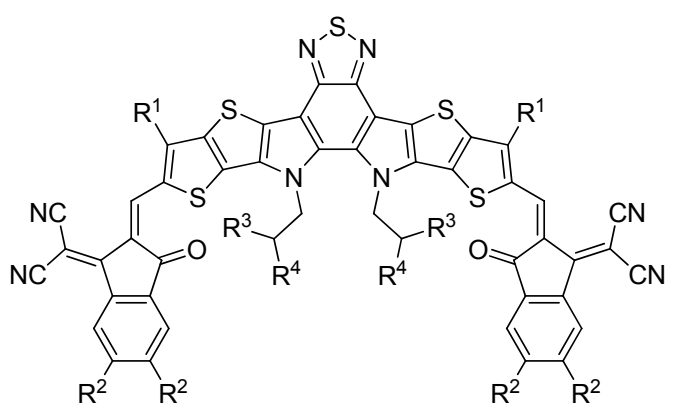

48: $\mathrm{R}^{1}=\mathrm{C}_{11} \mathrm{H}_{23}, \mathrm{R}^{2}=\mathrm{Cl}, \mathrm{R}^{3}=\mathrm{C}_{2} \mathrm{H}_{5}, \mathrm{R}^{4}=\mathrm{C}_{4} \mathrm{H}_{9}$ 49: $\mathrm{R}^{1}=\mathrm{C}_{11} \mathrm{H}_{23}, \mathrm{R}^{2}=\mathrm{Br}, \mathrm{R}^{3}=\mathrm{C}_{2} \mathrm{H}_{5}, \mathrm{R}^{4}=\mathrm{C}_{4} \mathrm{H}_{9}$

何凤课题组 ${ }^{[44]}$ 将系列溴代氰基䒢满二酮作为封端 基团用于 D-A-D 核心的小分子受体 49 51, 器件测试 表明含单溴代氰基狮满二酮封端的受体 51 表现最优. 这与该分子有着更高的摩尔消光系数和更高的 LUMO 能级, 有利于获得较高的 $J_{\mathrm{sc}}$ 和 $V_{\mathrm{oc}}$ 以及相分离更为优异 有关. 彭强课题组 ${ }^{[45]}$ 通过将 46 封端换成噻吩衍生物, 得到受体分子 52, 其 LUMO 能级比 46 高了 $0.2 \mathrm{eV}$, 有 利于提高器件光电压. 采用聚合物 PBDT-ST 为给体时, 基于 52 的光电池的电压达 $0.915 \mathrm{~V}$ (同等条件下基于 46 的器件仅为 $0.763 \mathrm{~V}$ ); 当加入结晶性更强的 PNDT-ST 为 第三组分时, 能够获得 $16.57 \%$ 的 PCE. 詹传郎课题组与 合作者 ${ }^{[46]}$ 报道了一个由氯代噻吩衍生物为封端的受体 53, 其与给体 HOMO 能级差值仅仅 $0.02 \mathrm{eV}$ 仍旧能够获 得超过 $15 \%$ 的 PCE. 通过添加第三组份调节空穴传输速 率与抑制电荷复合, 进一步提高了器件的 FF 使得电池 效率超过了 $16 \%$.

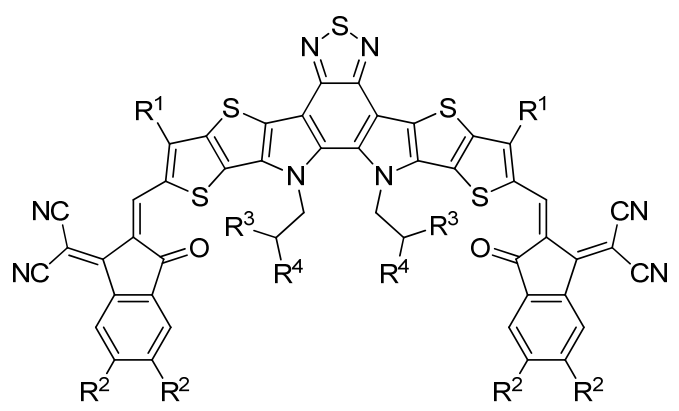

50: $\mathrm{R}^{1}=\mathrm{C}_{11} \mathrm{H}_{23}, \mathrm{R}^{2}=\mathrm{Br}, \mathrm{R}^{3}=\mathrm{C}_{4} \mathrm{H}_{9}, \mathrm{R}^{4}=\mathrm{C}_{6} \mathrm{H}_{13}$

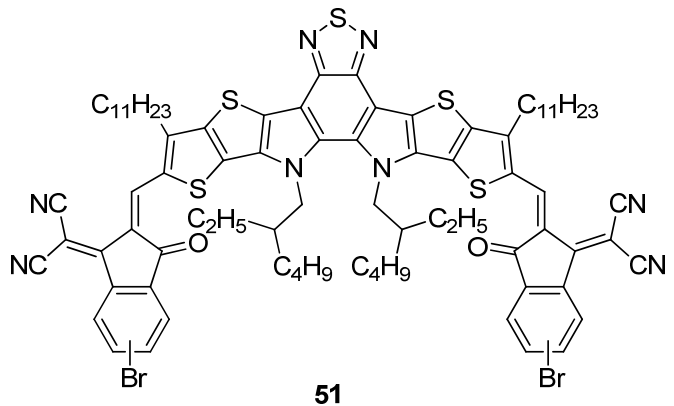

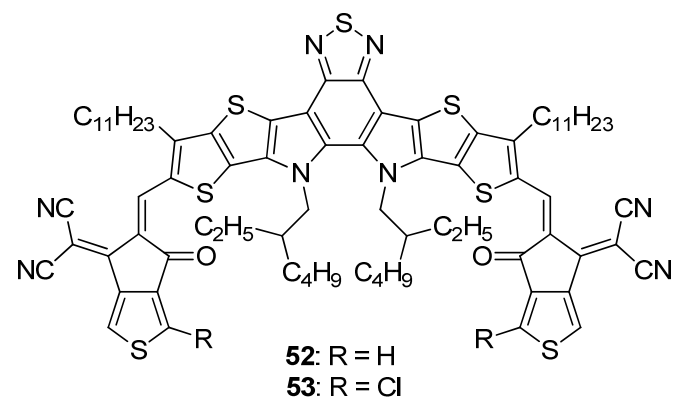

侧链工程是一种常见的提高有机太阳能电池材料 性能的设计策略. 颜河课题组与邹应萍课题组 ${ }^{[47]}$ 合作 对 46 的侧链进行了优化. 他们通过对 $\mathrm{N}$ 上的烷基链和 噻吩环上的侧链的笁选 $(54 \sim 56)$, 实现了溶解性与聚集 性的平衡. 当 $\mathrm{N}$ 上的取代基为 3-乙基庚基时(55), 获得 了比 46 更加优异的光伏性能. 在保持主体系给受体质 量比不变的情况下, 额外掺入 $\mathrm{PC}_{71} \mathrm{BM}$ 作为形貌调节剂, 制备出了第三方认证效率为 $16.42 \%$ 的三元有机光伏器 件. 杨楚罗课题组与合作者 ${ }^{[48]}$ 报道了与前述研究中结 构一样的两个受体分子 $(\mathbf{5 5}, \mathbf{5 6})$, 他们重点研究了 $\mathrm{N}$ 上 的取代基对这类受体材料的吸光范围、电子传输速率及 堆积方式的影响. 候剑辉课题组 ${ }^{[49]}$ 运用侧链工程这一 策略, 获得了小分子受体 $\mathbf{5 7}$ 和 58, 其中 57 较 48 的光伏 性能更加优秀. 以旋涂法制备的基于 57 的小面积电池 $\left(0.09 \mathrm{~cm}^{2}\right)$ 实现了高达 $17 \%$ 的能量转换效率，且当使用 刮刀涂布法制备 $1 \mathrm{~cm}^{2}$ 的大面积电池时, PCE 仍然能够 达到 $15.5 \%$. 最近，该课题组 ${ }^{[4]}$ 将 46 结构中 $\mathrm{N}$ 上的取代 基和噻吩环上的侧链变为 2-丁基辛基链和正壬基，同时 采用二氯代氰基狮满二酮封端得到了 59, 在小面积电 池中实现了接近 $18 \%$ 的能量转换效率.

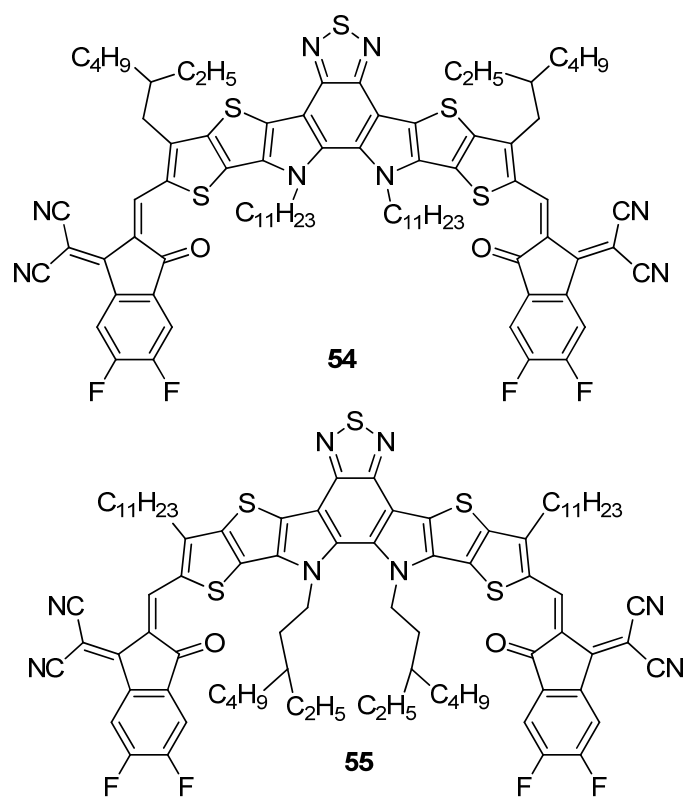




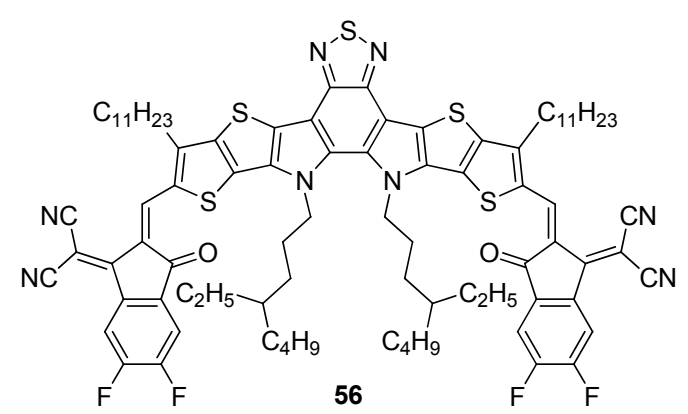

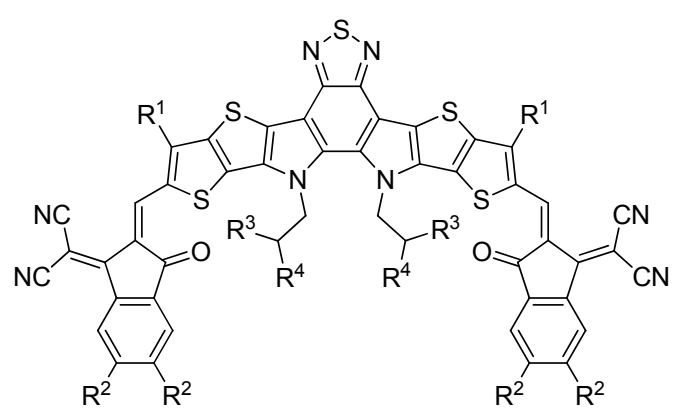

57: $\mathrm{R}^{1}=\mathrm{C}_{11} \mathrm{H}_{23}, \mathrm{R}^{2}=\mathrm{Cl}, \mathrm{R}^{3}=\mathrm{C}_{4} \mathrm{H}_{9}, \mathrm{R}^{4}=\mathrm{C}_{6} \mathrm{H}_{13}$ 58: $R^{1}=\mathrm{C}_{11} \mathrm{H}_{23}, \mathrm{R}^{2}=\mathrm{Cl}, \mathrm{R}^{3}=\mathrm{C}_{6} \mathrm{H}_{13}, \mathrm{R}^{4}=\mathrm{C}_{8} \mathrm{H}_{17}$ 59: $\mathrm{R}^{1}=\mathrm{C}_{9} \mathrm{H}_{19}, \mathrm{R}^{2}=\mathrm{Cl}, \mathrm{R}^{3}=\mathrm{C}_{4} \mathrm{H}_{9}, \mathrm{R}^{4}=\mathrm{C}_{6} \mathrm{H}_{13}$

詹传郎课题组 ${ }^{[50]}$ 通过对噻吩环上的侧链进行优化 得到了化合物 60 和 61 , 当噻吩环上为大位阻的 4-已基 苯基(61)时, 侧链不仅抑制了末端基团的旋转而且可以 使分子 LUMO 能级提高, 从而增强分子堆积性, 增加电 子迁移率, 有效抑制电荷复合, 最终导致器件的 $J_{\mathrm{sc}} 、 F F$ 和 $V_{\mathrm{oc}}$ 都得以提升, 获得了 $16.7 \%$ 的 PCE.

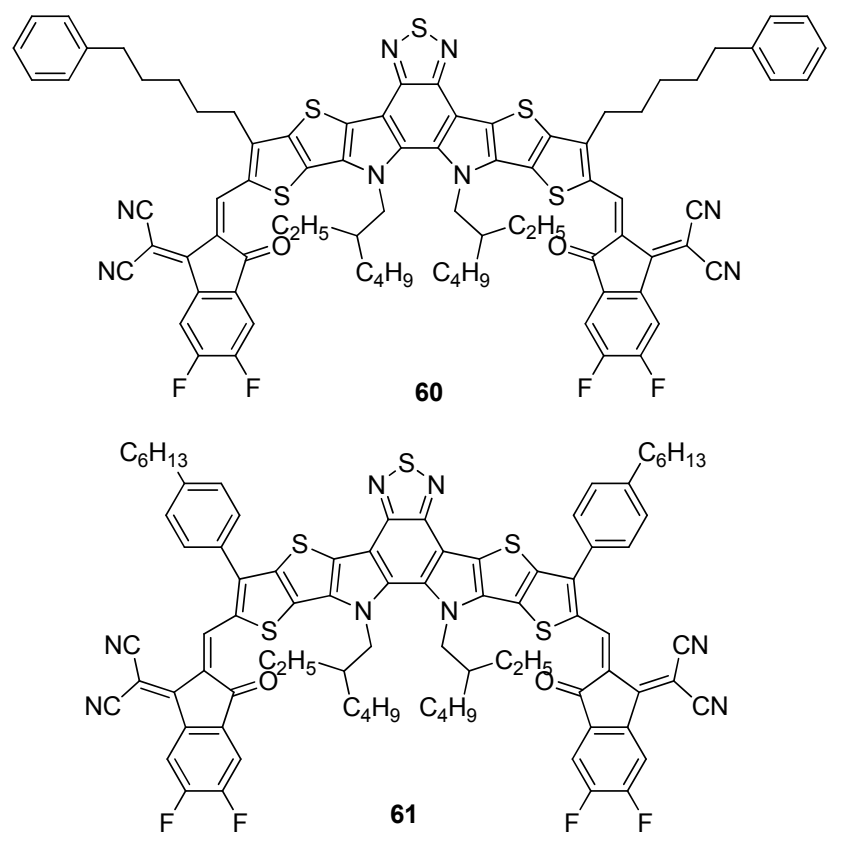

朱晓张课题组 ${ }^{[51]}$ 则采用了核心工程的策略将 46 的 D-A-D 结构中的“A”换成喹喔啉得到了两个新的小分子 受体 62 和 63. 化合物 62 的过强的结晶性可能是导致器
件双分子复合更为严重的原因，使得光电池的 $J_{\mathrm{sc}}$ 和 $F F$ 都明显低于以化合物 63 为受体的器件. 以化合物 63 和 聚合物给体 PM-6(原文中缩写为 PBDB-TF)组成的 20 片 太阳电池的统计结果如下: $V_{\mathrm{oc}}$ 为 $(0.86 \pm 0.01) \mathrm{V}, J_{\mathrm{sc}}$ 为 $(25.16 \pm 0.45) \mathrm{mA} / \mathrm{cm}^{2}, F F$ 为 $(75.80 \pm 1.03) \%$, PCE 为 $(16.43 \pm 0.14) \%$.

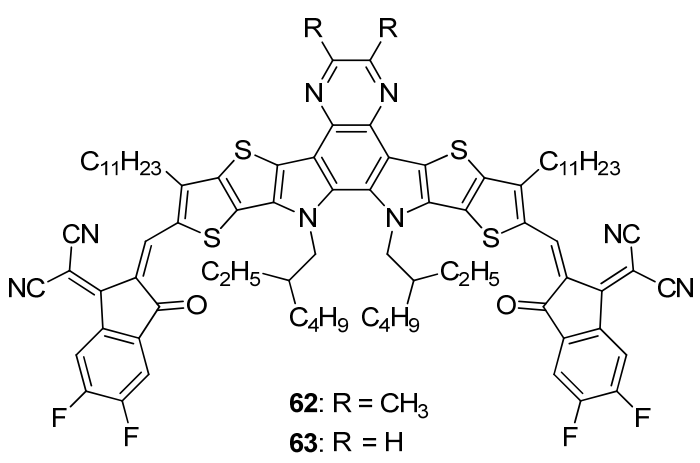

不对称结构是近年来兴起的一类小分子受体, 研究 者们将这一策略应用到了基于 D-A-D 稠环的受体分子 中. 杨楚罗课题组与张福俊课题组 ${ }^{[52]}$ 合作, 首次报道了 一个基于不对称 D-A-D 核心的小分子受体材料 64. 该 化合物与聚合物给体 PBDB-T-2Cl 组成的器件的 PCE 值 可达 $14.62 \%$; 当加入第三组分时, 以卷对卷工艺制备的 厚度为 $300 \mathrm{~nm}$ 的大面积三元有机太阳能电池亦能获得 $15.57 \%$ 的效率. 何风课题组与合作者 ${ }^{[53]}$ 合成了含两个 不同封端基团的不对称受体 $\mathbf{6 5}$. 这一化合物较大的偶 极矩有利于分子间的电荷迁移, 进而有利于得到高的 $J_{\mathrm{sc}}$. 颜河课题组与合作者 ${ }^{[54]}$ 通过封端基团的调控实现 了 $V_{\mathrm{oc}}$ 与 $J_{\mathrm{sc}}$ 提升的平衡, 不对称受体 $\mathbf{6 6}$ 所制备的电池获 得了比相应的对称型受体更高的效率.

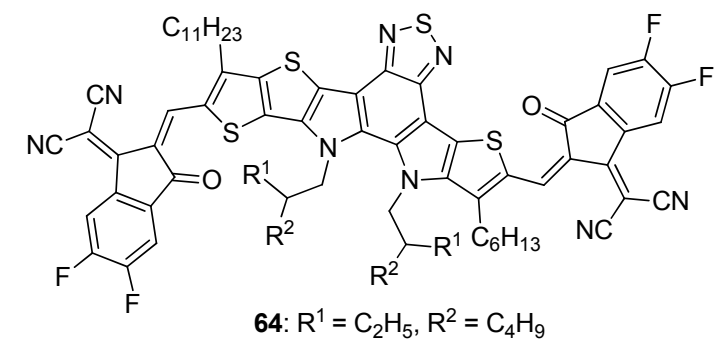

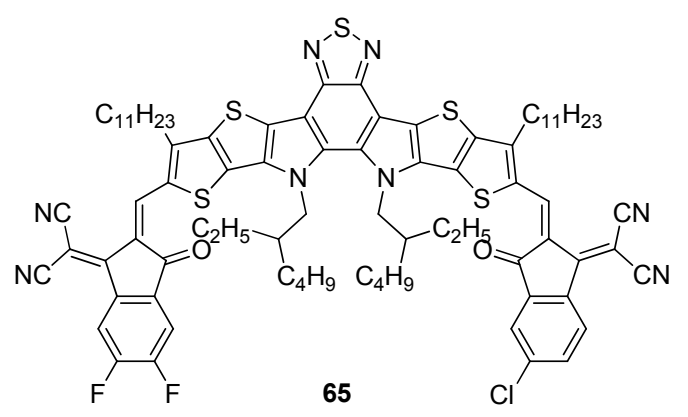




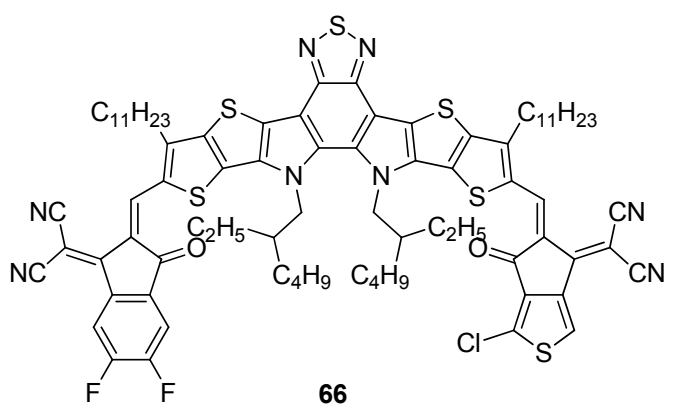

前述研究的器件中给体都是基于苯并二噻吩的聚 合物或者小分子, 最近研究表明在非苯并二噻吩衍生物 给体体系中, D-A-D 稠环为核心的受体小分子也有优异 的表现. 李永舫团队与合作者 ${ }^{[55]}$ 使用他们开发的含噻 吩和氟代喹喔啉的低成本 D-A 共聚物与化合物 $\mathbf{5 1}$ 组成 器件, 通过优化聚合物结构, 获得了 $16.32 \%$ 的 PCE. 候 剑辉课题组与张少青、叶龙等 ${ }^{[56]}$ 新近报道了一种不含氧 基的受体分子 67, 氧基的去除不仅明显降低了与聚(3-
己基噻吩)(P3HT)的混溶性，而且使得 LUMO 能级上移 实现了 $V_{\mathrm{oc}}$ 的提升. 最终所获得的光电池实现了近 $10 \%$ 的 PCE，这是目前基于 P3HT 的 OSCs 的最高记录.

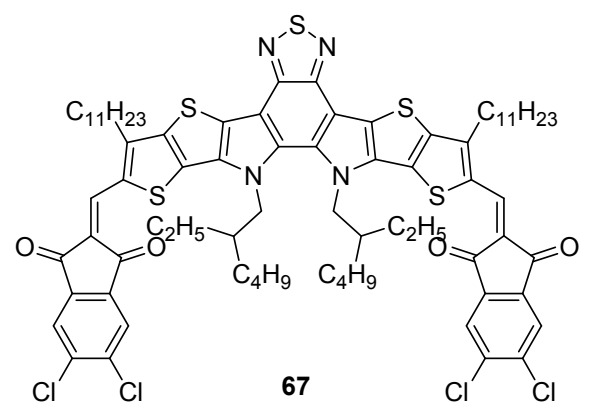

得益于基于 D-A-D 核心的小分子受体材料的开发, 在过去的一年里, 多个基于聚合物给体的 PCE 值超过 $16 \%$ 的研究被报道，表 2 中列出了本文涉及的小分子受 体所组成的二元有机太阳能电池的光伏性能数据, 目前

表 2 受体 38 67 电池器件的性能(与表不一致?)

Table 2 Performance of organic solar cells based on acceptors of $\mathbf{3 8} \sim \mathbf{6 7}$

\begin{tabular}{|c|c|c|c|c|c|c|}
\hline Compd. & Donor & $V_{\mathrm{oc}} / \mathrm{V}$ & $J_{\mathrm{sc}} /\left(\mathrm{mA} \cdot \mathrm{cm}^{-2}\right)$ & $F F / \%$ & PCE $/ \%$ & Ref \\
\hline 38 & HFQx-T & 0.84 & 12.67 & 59 & 6.3 & {$[32]$} \\
\hline 39 & PBDB-T & 0.87 & 22.44 & 69.1 & 13.42 & {$[31]$} \\
\hline 40 & PBDB-T & 0.82 & 23.56 & 69.4 & 13.40 & {$[31]$} \\
\hline 41 & PBDB-T & 0.90 & 23.28 & 63 & 13.26 & {$[33]$} \\
\hline 42 & PBDB-T & 0.914 & 21.33 & 66.69 & 13.00 & {$[34]$} \\
\hline 43 & PM-6 & 0.867 & 23.79 & 68.49 & 14.13 & {$[36]$} \\
\hline 44 & PM-6 & 0.832 & 26.74 & 74.33 & 16.54 & {$[37]$} \\
\hline 45 & $J-61$ & 0.90 & 21.1 & 58.3 & 11.0 & {$[38]$} \\
\hline 45 & TTFQx-1 & 0.89 & 21.2 & 69.6 & 13.1 & {$[38]$} \\
\hline 45 & PBDB-T & 0.88 & 22.8 & 70.2 & 14.1 & {$[38]$} \\
\hline 46 & PM-6 & 0.82 & 25.2 & 76.1 & 15.7 & {$[39]$} \\
\hline 46 & PM-6 (PBDB-TF) & 0.834 & 24.9 & 75.3 & 15.6 & {$[43]$} \\
\hline 46 & PM-6 & 0.841 & 25.19 & 77.3 & 16.37 & {$[54]$} \\
\hline 46 & BTR & 0.85 & 22.25 & 56.4 & 10.67 & {$[40]$} \\
\hline 46 & RTR-Cl & 0.86 & 24.17 & 65.5 & 13.61 & {$[40]$} \\
\hline 46 & BSFTR & 0.85 & 23.16 & 69.66 & 13.69 & {$[41]$} \\
\hline \multirow[t]{2}{*}{46} & P2F-EHp & 0.81 & 26.68 & 74.11 & 16.02 & {$[42]$} \\
\hline & PBDT-ST & 0.763 & 23.62 & 71.0 & 12.79 & {$[45]$} \\
\hline 47 & P2F-EHp & 0.78 & 3.20 & 43.78 & 1.09 & {$[42]$} \\
\hline 48 & PM-6 (PBDB-TF) & 0.867 & 25.4 & 75.0 & 16.5 & [43] \\
\hline 48 & P3HT & 0.50 & 5.16 & 0.39 & 1.01 & {$[56]$} \\
\hline 49 & PM-6 (PBDB-TF) & 0.87 & 20.65 & 41.76 & 7.51 & {$[44]$} \\
\hline 50 & PM-6 (PBDB-TF) & 0.86 & 24.06 & 67.84 & 14.03 & {$[44]$} \\
\hline 51 & PM-6 (PBDB-TF) & 0.88 & 25.03 & 73.13 & 16.11 & {$[44]$} \\
\hline 51 & PTQ10 & 0.92 & 17.25 & 58.2 & 9.24 & {$[55]$} \\
\hline 51 & PTQ11 & 0.88 & 24.79 & 74.8 & 16.32 & {$[55]$} \\
\hline 52 & PBDT-ST & 0.915 & 22.56 & 69.5 & 14.35 & {$[45]$} \\
\hline \multirow{2}{*}{53} & PM-6 & 0.877 & 24.4 & 70.4 & 15.1 & {$[46]$} \\
\hline & PM-6 & 0.885 & 23.46 & 69.8 & 14.49 & {$[54]$} \\
\hline 54 & PM-6 & 0.852 & 21.47 & 70.6 & 12.91 & [47] \\
\hline 55 & PM-6 & 0.837 & 25.81 & 73.9 & 15.98 & {$[47]$} \\
\hline 55 & PM-6 & 0.860 & 25.11 & 73.6 & 15.89 & {$[48]$} \\
\hline
\end{tabular}




\begin{tabular}{|c|c|c|c|c|c|c|}
\hline Compd. & Donor & $V_{\mathrm{oc}} / \mathrm{V}$ & $J_{\mathrm{sc}} /\left(\mathrm{mA} \cdot \mathrm{cm}^{-2}\right)$ & $F F / \%$ & $\mathrm{PCE} / \%$ & Ref. \\
\hline 56 & PM-6 & 0.819 & 25.01 & 69.9 & 14.31 & [47] \\
\hline 56 & PM-6 & 0.852 & 24.07 & 67.4 & 13.76 & [48] \\
\hline 57 & PM-6 & 0.858 & 25.6 & 77.6 & 17.0 & [49] \\
\hline 58 & PM-6 (PBDB-TF) & 0.862 & 24.2 & 74.8 & 15.6 & [49] \\
\hline 59 & PM-6 (PBDB-TF) & 0.839 & 26.2 & 81.1 & 17.8 & {$[4]$} \\
\hline 60 & PM-6 & 0.839 & 24.3 & 76.2 & 15.5 & [50] \\
\hline 61 & PM-6 & 0.865 & 25.0 & 77.0 & 16.7 & [50] \\
\hline 62 & PM-6 (PBDB-TF) & 0.89 & 22.18 & 67.14 & 13.31 & [51] \\
\hline 63 & PM-6 (PBDB-TF) & 0.86 & 25.38 & 76.25 & 16.64 & [51] \\
\hline 64 & PBDB-T-2Cl & 0.88 & 21.73 & 76.74 & 14.62 & [52] \\
\hline 65 & PM-6 (PBDB-TF) & 0.86 & 24.60 & 72.67 & 15.43 & [53] \\
\hline 66 & PM-6 & 0.869 & 25.38 & 77.4 & 17.06 & [54] \\
\hline 67 & P3HT & 0.88 & 16.49 & 0.65 & 9.46 & {$[56]$} \\
\hline
\end{tabular}
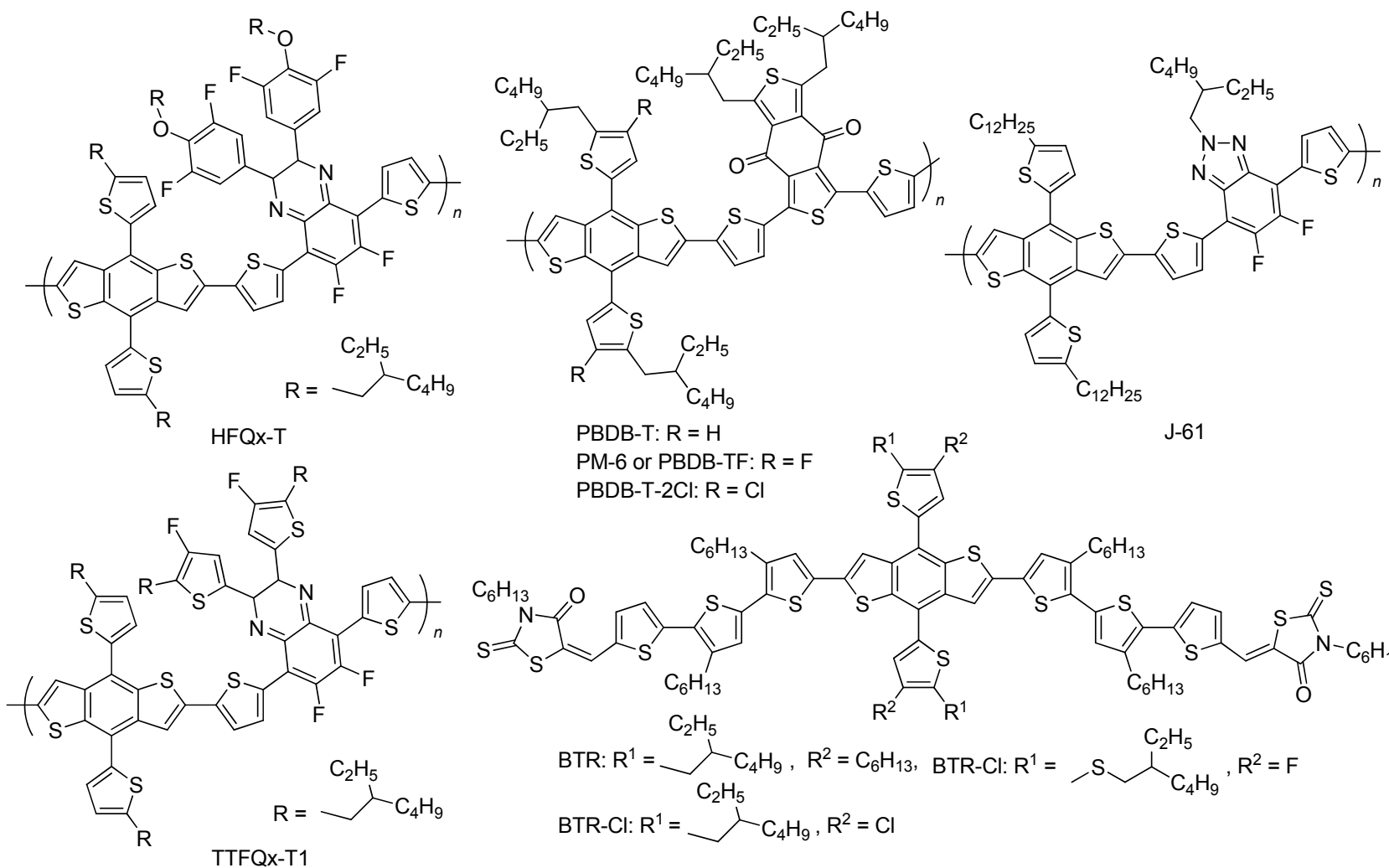

PBDB-T: $\mathrm{R}=\mathrm{H}$
PM-6 or PBDB-TF: $\mathrm{R}=\mathrm{F}$
PBDB-T-2Cl: $\mathrm{R}=\mathrm{Cl}$

$\mathrm{J}-61$

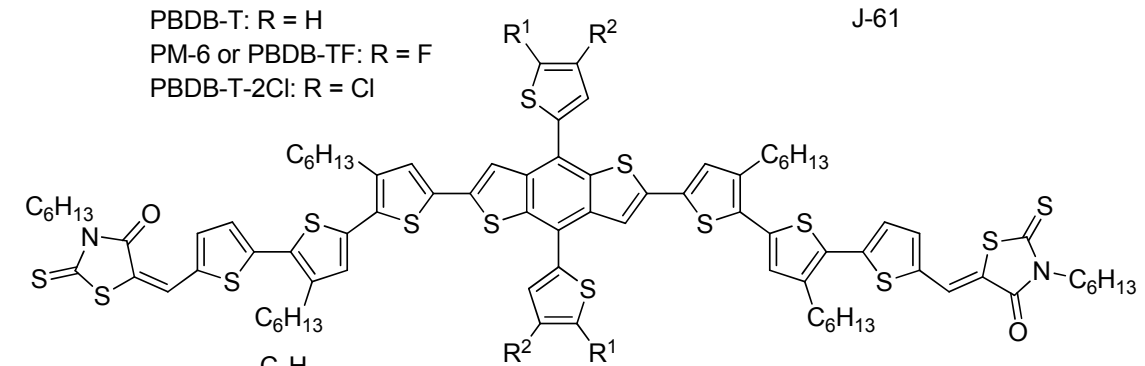

BTR: $\mathrm{R}^{1}=\overbrace{\mathrm{C}_{4} \mathrm{H}_{9}}^{\mathrm{C}_{2} \mathrm{H}_{5}}, \mathrm{R}^{2}=\mathrm{C}_{6} \mathrm{H}_{13}, \quad B T R-\mathrm{Cl}: \mathrm{R}^{1}=-\mathrm{S}_{\mathrm{C}_{4} \mathrm{H}_{9}}^{\mathrm{R}^{2}}, \mathrm{R}^{2}=\mathrm{F}$ BTR-Cl: $\mathrm{R}^{1}=\mathrm{C}_{4} \mathrm{H}_{9}, \mathrm{R}^{2}=\mathrm{Cl}$

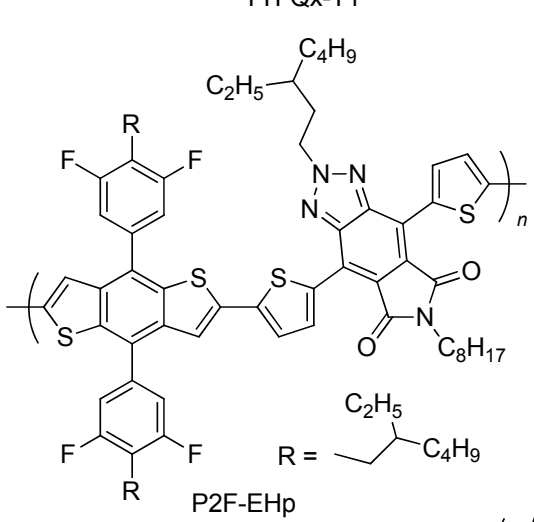

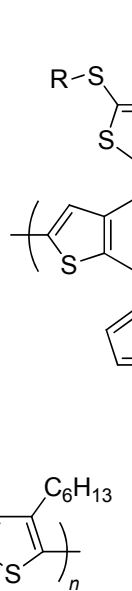

P3HT<smiles></smiles><smiles></smiles> 
全小分子有机太阳电池和三元有机太阳电池的光电转 换效率也在迅猛攀升. 值得注意的是, 这类材料在与低 成本的聚合物给体组成器件时也能获得优异的性能, 有 望推动 OSCs 早日产业化.

\section{4 基于 D-A-D 型稠环的空穴传输材料}

近年来, 有机一无机钙钋矿太阳能电池(PSCs)发展 迅速, 在短短十年里其光电转化效率从 $3.8 \%$ 迅速发展 到目前 $25.2 \%$ 的认证效率 ${ }^{[57]}$, 成为最有希望替代无机硅 电池的太阳能电池技术之一. 在 PSCs 中, 空穴传输材 料(hole-transport materials, HTM) 在提升钙钛矿太阳能 电池的效率和稳定性方面扮演着很重要的角色. 迄今为 止, 使用和研究最普遍的有机小分子 HTM 是 2,2',7,7'四 ( N,N-二对甲氧基苯基胺)-9,9'- 螺 - 二荡 (SpiroOMeTAD), 但是它的合成路线复杂, 价格高昂, 限制了 PSCs 的商业化应用. D-A-D 型稠环具有大平面共轭结 构, 有利于获得较高的空穴传输速率, 其衍生物可以被 用作 HTM 以制备高效的钙铁矿太阳能电池.

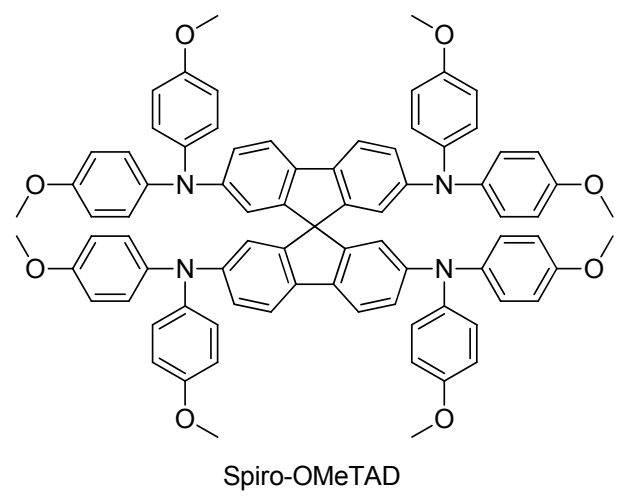

黄祖胜课题组 ${ }^{[58]}$ 合成了三种以 DTPBT 为核心的 HTM (68 70), 他们与王鸣魁课题组合作将这些材料 应用于 PSCs 中. 化合物 70 以 $N$-正辛基吩噻嗪为芳胺基, 空间限流法(SCLC)测试表明其空穴传输速率在这三种 材料中最高, 达 $4.80 \times 10^{-4} \mathrm{~cm}^{2} \cdot \mathrm{V}^{-1} \cdot \mathrm{s}^{-1}$. 以之为空穴传 输层的器件取得了与经典 HTM spiro-OMeTAD 相媲美 的 PCE，并且在未封装、相对湿度为 $20 \%$ 的条件下可以 稳定工作超过 $280 \mathrm{~h}$. 受这一结果的激励, 他们 ${ }^{[59]}$ 合成 了含有 DTBT 的 $\operatorname{HTM}(\mathbf{7 1}, \mathbf{7 2})$. 其中, 化合物 71 在不掺 杂双 (三氟甲磺酰基)胺锂盐(Li-TFSI)和 4-叔丁基吡啶 (TPB)为添加剂的情况下, 超过了以 spiro-OMeTAD 为 HTM 的 PCE; 在使用添加剂的情况下, 基于化合物 72 的器件获得了 $15.77 \%$ 的 PCE $\left(J_{\mathrm{sc}}=22.82 \mathrm{~mA} \cdot \mathrm{cm}^{-2}\right.$, $V_{\text {oc }}=1.00 \mathrm{~V}, F F=0.69$ ).

郭旭岗课题组与合作者 ${ }^{[5,60]}$ 开发了基于 BTI 和 BTTI 为核心的 HTM $(\mathbf{7 3} \sim 76)$. 较之 BTI, BTTI 具有更大的共

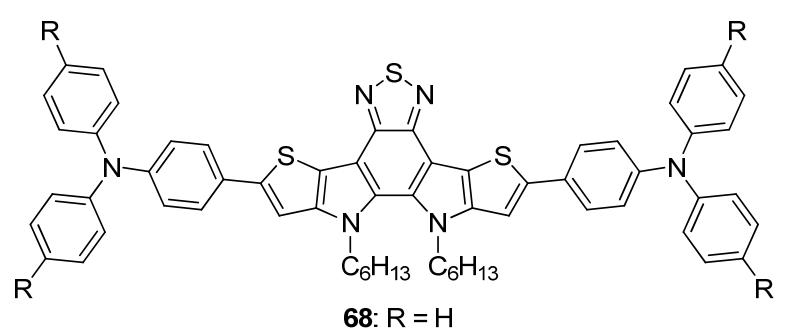

69: $\mathrm{R}=\mathrm{OC}_{6} \mathrm{H}_{13}$

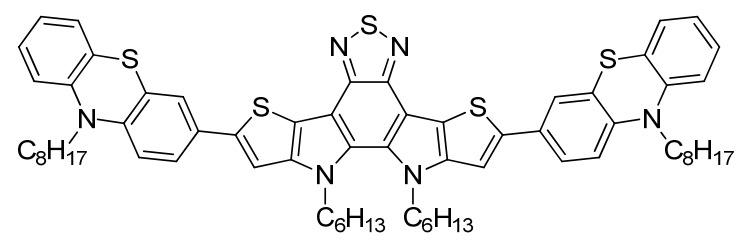

70

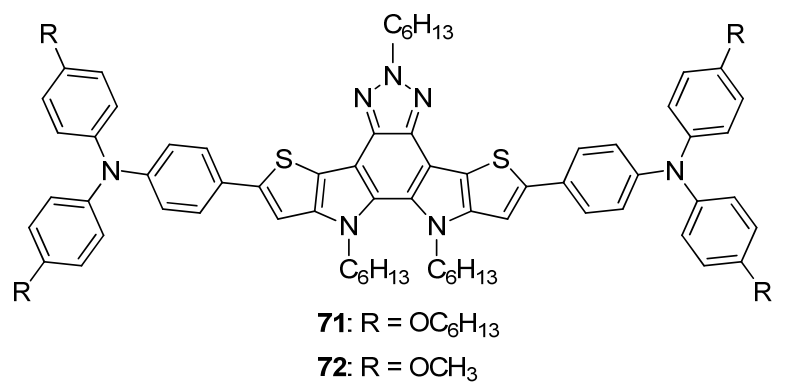

轭结构, 因此化合物 74 比化合物 $\mathbf{7 3}$ 的空穴传输速率高 了一个数量级. 在无掺杂的条件下, 化合物 74 获得了 $1.12 \mathrm{~V}$ 的 $V_{\mathrm{oc}}$, 超过 $23 \mathrm{~mA} \cdot \mathrm{cm}^{-2}$ 的 $J_{\mathrm{sc}}, F F$ 大于 $80 \%$, PCE 高于 $21 \%$, 高于氧化镍等许多常见材料为 HTM 的器 件 ${ }^{[3]}$. 基于化合物 74 的器件在在相对湿度为 $20 \%$ 、暗态 下，保存 $60 \mathrm{~d}$ 之后，仍能保持初始 PCE 的 $90 \%$; 而在 $25{ }^{\circ} \mathrm{C}$ 相对湿度为 $30 \% \sim 40 \%$ 条件下的持续辐照实验中, 器件工作约 $500 \mathrm{~h}$ 后依旧能够保持初始 PCE 的 $90 \%$. 他

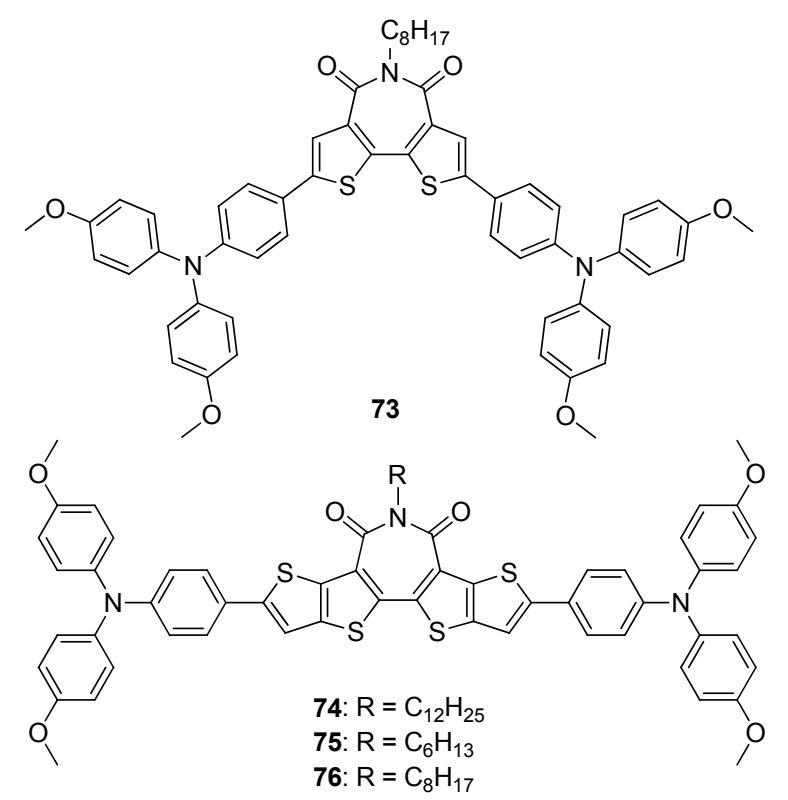


们在氧化锡为电子传输材料的 PSCs 中, 详细研究了 BTTI 核心上烷基侧链的长度对器件效率的影响, 烷基 链对空穴传输速率、成膜性能及器件性能有着极大的影 响，其中正己基侧链获得了最佳的 $\mathrm{PCE}^{[60]}$.

目前, 基于 D-A-D 型稠环的 HTM 报道不多, 表 3 总结了本文涉及的 HTM 组成的 PSCs 的性能参数, 基于 这类材料的 PSCs 均显示了良好的稳定性，尤其在免掺 杂 PSCs 上显示出良好的应用前景, 有望成为 HTM 材料 开发的新热点.

表 3 基于空穴传输材料 $68 \sim 76$ 的钙钛矿电池器件的性能 Table 3 Performance of perovskite solar cells based on HTMs of $68 \sim 76$

\begin{tabular}{cccccc}
\hline Compd. & $V_{\mathrm{oc}} / \mathrm{V}$ & $J_{\mathrm{sc}} /\left(\mathrm{mA} \cdot \mathrm{cm}^{-2}\right)$ & $F F / \%$ & $\mathrm{PCE} / \%$ & Ref. \\
\hline $\mathbf{6 8}$ & $0.829^{a}$ & $18.30^{a}$ & $46^{a}$ & $7.0^{a}$ & {$[58]$} \\
$\mathbf{6 9}$ & $0.921^{a}$ & $19.44^{a}$ & $57^{a}$ & $10.2^{a}$ & {$[58]$} \\
$\mathbf{7 0}$ & $1.026^{a}$ & $20.43^{a}$ & $68^{a}$ & $14.2^{a}$ & {$[58]$} \\
$\mathbf{7 1}$ & 0.950 & 19.78 & 57 & 10.73 & {$[59]$} \\
$\mathbf{7 2}$ & $0.990(1.00)^{a}$ & $20.72(22.82)^{a}$ & $64(69)^{a}$ & $13.22(15.77)^{a}[59]$ \\
$\mathbf{7 3}$ & 1.090 & 21.58 & 73.7 & 17.20 & {$[5]$} \\
$\mathbf{7 4}$ & 1.120 & 23.23 & 81.4 & 21.17 & {$[5]$} \\
$\mathbf{7 5}$ & 1.030 & 24.26 & 69.91 & 17.49 & {$[60]$} \\
$\mathbf{7 6}$ & 1.100 & 24.00 & 74.6 & 19.69 & {$[60]$} \\
\hline
\end{tabular}

${ }^{a}$ Dopanted by Li-TFSI and TPB

\section{5 结论与展望}

综上所述，通过对基于 D-A-D 型稠环模块的小分 子光伏材料进行分析, 可以看出 D-A-D 型稠环结构的 设计对其光电性能有着显著的影响，具体说来包括稠环 结构中的给体部分的给电子能力、受体部分的吸电子能 力和取代基结构及位置等. D-A-D 型稠环衍生物具有较 合适的 HOMO 能级和较好的载流子传输性能, 已经成 为了在小分子受体及空穴传输材料等领域的研究热点. 由于这类材料的开发, 当前转换效率超过 $16 \%$ 的 OSCs 越来越多，免掺杂的 PSCs 的效率也突破了 $21 \%$ ，屡屡 刷新着各自领域的最高记录, 显示了该类稠环砌块极为 诱人的应用前景. 未来基于 D-A-D 型稠环的光伏材料 的研究主要有以下几个方面：(1)尚未有超过 10\%的 D-A-D 型稠环染料敏化的太阳电池被报道, 为了进一步 提升该类材料的光伏性能, 需要在已报道的分子结构特 点与光电性能关系的基础上，去进一步设计合成新型 D-A-D 型稠环染料以提高器件的电压与电流, 并积极尝 试将之应用于准固态或固态染料敏化太阳能电池中. (2) 在过去的一年多时间里, 以 D-A-D 型稠环为核心的小 分子受体材料取得了非常瞩目的进展, 然而这类材料的
开发以尝试为主，期待材料物理学家的进一步努力以对 这类材料的工作机制做更为深入的研究以便形成理论 指导; 同时，将此类材料用于叠层有机太阳能电池或者 杂化太阳能电池的研究有望推动有机太阳能电池的大 规模应用; 另一方面，积极尝试合成基于已报道的 D-A-D 型稠环核心的不对称受体或者基于新型 D-A-D 型稠环模块的小分子受体，实现能隙和结晶性的精细调 控或吸光范围的进一步拓宽，有望推动小分子太阳能电 池的光伏性能的进一步提升. (3) 载流子迁移率高是 D-A-D 型稠环作为免掺杂空穴传输材料的一大优势, 然 而这方面的研究尚不多见，有待材料化学家合成更多的 基于这类模块的空穴传输材料，以期获得光热稳定性更 好的、光伏性能更优异的 PSCs 器件, 同时对于器件机 理方面也需要进一步深入研究，包括载流子的分离、传 输与收集等. 此外，设计合成新型 D-A-D 型稠环、发展 高效快捷的 D-A-D 型稠环的合成方法以降低此类材料 的合成难度与使用成本也是未来研究努力的方向.

\section{References}

[1] Wang, Y.; Michinobu, T. J. Mater. Chem. C 2016, 4, 6200.

[2] Geng, Y.; Tang, A.; Tajima, K.; Zeng, Q.; Zhou, E. J. Mater. Chem. A 2019, 7, 64 .

[3] Godfroy, M.; Aumaitre, C.; Caffy, F.; Kervella, Y.; Cabau, L.; Pellejà, L.; Maldivi, P.; Narbey, S.; Oswald, F.; Palomares, E.; Joly, D.; Demadrille, R. Dyes Pigm. 2017, 146, 352.

[4] Cui, Y.; Yao, H.; Zhang, J.; Xian, K.; Zhang, T.; Hong, L.; Wang, Y.; Xu, Y.; Ma, K.; An, C.; He, C.; Wei, Z.; Gao, F.; Hou, J. Adv. Mater. 2020, 32, 1908205.

[5] Wang, Y.; Chen, W.; Wang, L.; Tu, B.; Chen, T.; Liu, B.; Yang, K.; Koh, C.; Zhang, X.; Sun, H.; Chen, G.; Feng, X.; Woo, H.; Djurišić, A.; He, Z.; Guo, X. Adv. Mater. 2019, 31, 1902781.

[6] Cheng, Y.; Chen, C.; Ho, Y.; Chang, S.; Witek, H.; Hsu, C. Org. Lett. 2011, 13, 5484.

[7] Arroyave, F.; Richard, C.; Reynolds, J. Org. Lett. 2012, 14, 6138.

[8] O'Regan, B.; Grätzel, M. Nature 1991, 353, 737.

[9] Grätzel, M. Nature 2001, 414, 338.

[10] Grätzel, M. Acc. Chem. Res. 2009, 42, 1788.

[11] Ooyama, Y.; Harima, Y. ChemPhys Chem 2012, 13, 4032.

[12] Qu, S.; Hua, J.; Tian, H. Sci. China: Chem. 2012, 42, 567.

[13] Luo, J.; Wan, Z.; Jia, C. Chin. Chem. Lett. 2016, 27, 1304

[14] Huang, Z; Meier, H.; Cao, D. J. Mater. Chem. C 2016, 4, 2404.

[15] Tian, Y.; Cai, N.; Chen, Y.; Qian, S.; Huo, Y. Chin. J. Org. Chem. 2018, 38, 1085 (in Chinese).

(田亚娟, 蔡宁, 陈亚通, 钱赛男, 霍延平, 有机化学, 2018, 38, 1085.)

[16] Huang, Z.; Feng, H.; Zang X.; Iqbal, Z.; Zeng, H.; Kuang, D.; Wang, L.; Meier, H.; Cao, D. J. Mater. Chem. A 2014, 2, 15365.

[17] Huang, Z.; Hua, T.; Tian, J.; Wang, L.; Meier, H.; Cao, D. Dyes Pigm. 2016, 125, 229.

[18] Ni, J.; You, J.; Hung, W.; Kao, W.; Chou, H.; Lin, J. ACS Appl. Mater. Int. 2014, 6, 22612.

[19] Richard, C.; Pan, Z.; Hsu, H.; Cekli, S.; Schanze, K.; Reynolds, J. ACS Appl. Mater. Int. 2014, 6, 5221.

[20] Richard, C.; Pan, Z.; Parthasarathy, A.; Arroyave, F.; Estrada, L.; Schanzeb, K.; Reynolds, J. J. Mater. Chem. A 2014, $2,9866$.

[21] Huang, Z.; Zang, X.; Hua, T.; Wang, L.; Meier, H.; Cao, D. ACS Appl. Mater. Interfaces 2015, 7, 20418.

[22] Ni, J.; Kao, W.; Chou, H.; Lin, J. ChemSusChem 2015, 8, 2932.

[23] Ni, J.; Chiu, T.; Kao, W.; Chou, H.; Su, C.; Lin, J. ACS Appl. Mater. 
Int. 2016, 8, 23066.

[24] Lin, Y.; Zhan, X. Adv. Energy Mater. 2015, 5, 1501063.

[25] Dai, S.; Zhan, X. Acta Polym. Sinica 2017, 1706 (in Chinese). (代水星, 占肖卫, 高分子学报, 2017, 1706.)

[26] Lin, Y.; Wang, J.; Zhang, Z.; Bai, H.; Li, Y.; Zhu, D.; Zhan, X. Adv. Mater. 2015, 27, 1170.

[27] Yan, C.; Barlow, S.; Wang, Z.; Yan, H.; Jen, A.; Marder, S.; Zhan, X. Nat. Rev. Mater. 2018, 3, 18003.

[28] Lin, Y.; Li, Y.; Zhan, X. Chem. Soc. Rev. 2012, 41, 4245.

[29] Lin, Y.; Zhan, X. Acc. Chem. Res. 2016, 49, 175.

[30] Lin, Y.; Zhang, Z.; Bai, H.; Wang, J.; Yao, Y.; Li, Y.; Zhu, D.; Zhan, X. Energy Environ. Sci. 2015, 8, 610.

[31] Yuan, J.; Huang, T.; Cheng, P.; Zou, Y.; Zhang, H.; Yang, J.; Chang, S.; Zhang, Z.; Huang, W.; Wang, R.; Meng, D.; Gao, F.; Yang, Y. Nat. Commun. 2019, 10, 570.

[32] Feng, L.; Yuan J.; Zhang, Z.; Peng, H.; Zhang, Z.; Xu, S.; Liu, Y.; Li, Y.; Zou, Y. ACS Appl. Mater. Interfaces 2017, 9, 31985.

[33] Luo, M.; Zhou, L.; Yuan, J.; Zhu C.; Cai, F.; Hai, J.; Zou, Y. J. Energy Chem. 2020, 42, 169.

[34] Ma, X.; Luo, M.; Gao, W.; Yuan, J.; An, Q.; Zhang, M.; Hu, Z.; Gao, J.; Wang, J.; Zou, Y.; Yang, C.; Zhang, F. J. Mater. Chem. A 2019, 7, 7843

[35] Dai, S.; Zhao, F.; Zhang, Q.; Lau, T.; Li, T.; Liu, K.; Ling, Q.; Wang, C.; Lu, X.; You, W.; Zhan, X. J. Am. Chem. Soc. 2017, 139, 1336.

[36] Luo, M.; Zhu, C.; Yuan, J.; Zhou, L.; Keshtov, M.; Godovsky, D.; Zou, Y. Chin. Chem. Lett. 2019, 30, 2343.

[37] Liu, S.; Yuan, J.; Deng, W.; Luo, M.; Xie, Y.; Liang, Q.; Zou, Y.; He, Z.; Wu, H.; Cao, Y. Nat. Photonics 2020, 14, 300.

[38] Yuan, J.; Zhang, Y.; Zhou, L.; Zhang, C.; Lau, T.; Zhang, G.; Lu, X.; Yip, H.; So, S.; Beaupré, S.; Mainville, M.; Johnson, P.; Leclerc, M.; Chen, H.; Peng, H.; Li, Y.; Zou, Y. Adv. Mater. 2019, 31, 1807577.

[39] Yuan, J.; Zhang, Y.; Zhou, L.; Zhang, G.; Yip, H.; Lau, T.; Lu, X.; Zhu, C.; Peng, H.; Johnson, P.; Leclerc, M.; Cao, Y.; Ulanski, J.; Li, Y.; Zou, Y. Joule 2019, 3, 1140.

[40] Chen, H.; Hu, D.; Yang, Q.; Gao, J.; Fu, J.; Yang, K.; He, H.; Chen, S.; Kan, Z.; Duan, T.; Yang, C.; Ouyang, J.; Xiao, Z.; Sun, K.; Lu, S. Joule 2019, 3, 3034.

[41] Yue, Q.; Wu, H.; Zhou, Z.; Zhang, M.; Liu, F.; Zhu, X. Adv. Mater. 2019, 31, 1904283.

[42] Fan, B.; Zhang, D.; Li, M.; Zhong, W.; Zeng, Z.; Ying, L.; Huang, F.; Cao, Y. Sci. China: Chem. 2019, 62, 746.

[43] Cui, Y.; Yao, H.; Zhang, J.; Zhang, T.; Wang, Y.; Hong, L.; Xian,
K.; Xu, B.; Zhang, S.; Peng, J.; Wei, Z.; Gao, F.; Hou, J. Nat. Commun. 2019, 10, 2515.

[44] Wang, H.; Liu, T.; Zhou, J.; Mo, D.; Han, L.; Lai, H.; Chen, H.; Zheng, N.; Zhu, Y.; Xie, Z.; He, F. Adv. Sci. 2020, 7, 1903784.

[45] Xu, X.; Feng, K.; Lee, Y.; Woo, H.; Zhang, G.; Peng, Q. Adv. Funct. Mater. 2020, 30, 1907570.

[46] Li, X.; Pan, M.; Lau, T.; Liu, W.; Li, K.; Yao, N.; Shen, F.; Huo, S.; Zhang, F.; Wu, Y.; Li, X.; Lu, X.; Yan, H.; Zhan, C. Chem. Mater. 2020, 32, 5182 .

[47] Jiang, K.; Wei, Q.; Lai, J.; Peng, Z.; Kim, H.; Yuan, J.; Ye, L.; Ade, H.; Zou, Y.; Yan, H. Joule 2019, 3, 3020.

[48] Luo, Z.; Sun, R.; Zhong, C.; Liu, T.; Zhang, G.; Zou, Y.; Jiao, X.; Min, J.; Yang, C. Sci. China: Chem. 2020, 63, 361.

[49] Cui, Y.; Yao, H.; Hong, L.; Zhang, T.; Tang, Y.; Lin, B.; Xian, K.; Gao, B.; An, C.; Bi, P.; Ma, W.; Hou, J. Nat. Sci. Rev. 2019 nwz200.

[50] Chai, G.; Chang, Y.; Peng, Z.; Jia, Y.; Zou, X.; Yu, D.; Yu, H.; Chen, Y.; Chow, P.; Wong, K.; Zhang, J.; Ade, H.; Yang, L.; Zhan, C. Nano Energy 2020, 76, 105087.

[51] Zhou, Z.; Liu, W.; Zhou, G.; Zhang, M.; Qian, D.; Zhang, J.; Chen, S.; Xu, S.; Yang, C.; Gao, F.; Zhu, H.; Liu, F.; Zhu, X. Adv. Mater. 2020, 32, 1906324.

[52] Gao, J.; Gao, W.; Ma, X.; Hu, Z.; Xu, C.; Wang, X.; An, Q.; Yang, C.; Zhang, X.; Zhang, F. Energy Environ. Sci. 2020, 13, 958.

[53] Lai, H.; Chen, H.; Zhu, Y.; Chen, L.; Huang, H.; He, F. J. Mater. Chem. A 2020, 8, 96706.

[54] Luo, Z.; Ma, R.; Liu, T.; Yu, J.; Xiao, Y.; Sun, R.; Xie, G.; Yuan, Y.; Chen, Y.; Chen, K.; Chai, G.; Sun, H; Min, J.; Zhang, J.; Zou, Y.; Yang, C.; Lu, X.; Gao, F.; Yan, H. Joule 2020, 4, 1236.

[55] Sun, C.; Qin, S.; Wang, R.; Chen, S.; Pan, F.; Qiu, B.; Shang, Z.; Meng, L.; Zhang, C.; Xiao, M.; Yang, C.; Li, Y. J. Am. Chem. Soc. 2020, 142,1465 .

[56] Yang, C.; Zhang, S.; Ren, J.; Gao, M.; Bi, P.; Ye, L.; Hou, J. Energy Environ. Sci. 2020, 13, 2864.

[57] Best Research-Cell Efficiency Chart, [2020-03-11] https://www. nrel.gov/pv/cell-efficiency.html.

[58] Zhao, X.; Quan, Y.; Pan, H.; Li, Q.; Shen, Y.; Huang, Z.; Wang, M. J. Energy Chem. 2019, 32, 85.

[59] Ye, X.; Zhao, X.; Li, Q.; Ma, Y.; Song, W.; Quan, Y.; Wang, Z.; Wang, M.; Huang, Z. Dyes Pigm. 2019, 164, 407.

[60] Tu, B.; Wang, Y.; Chen, W.; Liu, B.; Feng, X.; Zhu, Y.; Yang, K.; Zhang, Z.; Shi, Y.; Guo, X.; Li, H.; Tang, Z.; Djurišić, A.; He, Z. ACS Appl. Mater. Interfaces 2019, 11, 48556. 